\title{
A repeat-sales index for pricing US corporate bonds
}

\author{
Renaud Beaupain ${ }^{1}$, Stephanie Heck ${ }^{2}$
}

\begin{abstract}
In this paper we use a repeat-sales index methodology to construct US corporate bond price indices. Using several performance tests, we show that this methodology provides superior index estimates. In particular when assets trade at infrequent and irregular intervals the repeat-sales index is superior to taking an arithmetic price average. The methodology can readily be applied to any sub-sample of bonds based on a particular characteristic, such as the rating or the maturity. We further study the sensitivity of individual bond returns to systematic market risk as measured by a repeat-sales price index. Results indicate that variations in the price index are an important determinant of the time series and of the cross-sectional variation of corporate bond returns.
\end{abstract}

\section{Introduction}

In this paper we develop a new price index for US corporate bonds and we use this index to study the cross-section of corporate bond returns. Being an over-the-counter (OTC) market, the US corporate bond market is typically associated with less price transparency. Dealers can quote different prices from one customer to another and trades result from a bilateral bargaining process. Trades are less frequent and regular than on stock markets for instance. Furthermore with its own indenture, each bond is unique in terms of maturity, interest payment schedule or convertibility. Designing a price index in this context is challenging and we provide a new way of

1. IESEG School of Management (LEM-CNRS), r.beaupain@ieseg.fr

2. HEC Liège, Management School of the University of Liège, stephanie.heck@ulg.ac.be

The authors thank Pascal François (the Editor), Marco Pagano, Thierry Foucault, Alain Durré, Georges Hübner, Koen Inghelbrecht, Marie Lambert, Mikael Petitjean, Christophe Desagre, José Dolores, an anonymous referee, as well as seminar participants at the 2015 CESAM Market Liquidity Workshop, the Belgian Financial Research Forum 2016, the $33^{\text {rd }}$ International Conference of the French Finance Association, the Paris Financial Management Conference 2016 and the 2016 PhD Colloquium (Liège, Luxembourg, Aachen, Maastricht) for useful comments and suggestions. Stephanie Heck gratefully acknowledges financial support from the FRS-FNRS. 
computing a price index for the corporate bond market. As our results suggest, our index has the ability to deal with infrequent trades and to take into account the price information conveyed by all observed transactions. The methodology is inspired from the repeat-sales price index, successfully used for building price indices in the real estate market. ${ }^{3}$ We argue that this methodology can be very useful in the setting of an OTC market, where few trades are observed on a specific bond. Furthermore, as is the case for houses, the corporate bond market offers a large diversity of products, with almost no bond being identical. The methodology is appealing when facing a large heterogeneity of assets and it can be applied to any category or subset of bonds, thereby easing the comparison between different categories.

While the scope of index products in the fixed income market has grown substantially, none of the classical indices is constructed with this methodology. As discussed in Brown (2002), indices fulfil two main roles. First, indices are important as a benchmark of price evolution. Second, they are important benchmark tools in the field of portfolio management. Brown (2002) and Martellini et al. (2003) present the standardised rules for calculating bond indices. In the particular case of the corporate bond market, investors can choose from a broad spectrum of market indices to obtain a representative benchmark to measure risk and return. However, indices are most of the time designed to capture the price evolution of some specific bond category. Typically, many index providers define an index for the investment-grade segment versus the high-yield segment, or for a specific rating or maturity category. ${ }^{4}$ Additional rules on the amount outstanding, the coupon rate, the currency, or the taxation further contribute to the selection of specific bonds for one index.

From a portfolio management perspective indices are needed as reliable benchmarks to assess the outcome of an investment strategy. Currently, when assessing the performance of her portfolio a manager's choice is merely limited to a list of established indices, which might lack flexibility in the definition of the bond universe considered. As the assessment of any portfolio strategy depends on the chosen benchmark (Elton et al., 1993), having a reliable index is of crucial importance. Using a broader index should provide the additional advantage of allowing for a more accurate

3. Repeat-sales indices are also used in markets for other thinly-traded assets such as art and wine. See, e.g., Ashenfelter and Graddy (2003) or Dimson et al. (2015).

4. For a review of US and European corporate bond indices, we refer to Goltz and Campani (2011). 
performance measurement of funds composed of corporate bonds. The recent crisis has highlighted problems associated with securities traded in OTC markets. One of the major concerns was the inability to correctly value securities traded in these markets and as a consequence the inability to trade them. Several investment-grade indices exist in the US market, but they can display different evolutions, mainly due to the specific sample of bonds included in their computations. A more general method, less driven by characteristics, might be required to provide a picture of the aggregate price evolution in the market.

To this purpose, the repeat-sales index is an appealing technique as it does not require any minimum number of trades per asset and can include all bonds in a given category, under the assumption that the characteristics of individual assets do not change markedly between trades. Although the repeat-sales methodology does not account for such individual bond features directly it nevertheless provides the advantage of being readily applicable to any subset or category of bonds and thereby yields comparable quantities. By contrast, reference indices provided by several private institutions can hardly be compared among each other since their construction methods and inclusion rules diverge. Further in opposition to other classic indices, the repeat-sales index does not rely on a weighted average of individual returns or prices.

In this paper we demonstrate the accuracy of a repeat-sales price index for the corporate bond market. This technique offers a novel approach for the construction of a corporate bond index, by accounting for some of the market specificities. There is evidence that this methodology has been used for corporate bond data but without formal justification on the adequacy of this index or its estimation method. For instance, in the literature on transaction costs, Edwards et al. (2007) require the use of an aggregate index in the estimation of transaction costs and use a repeat-sales price index. The accuracy of this estimation procedure for the corporate bond market has however never been tested empirically.

This price index can be useful beyond its role as a price benchmark. Under the Capital Asset Pricing Model only systematic risk is priced and this risk is measured by an asset's exposure (the beta) to the market portfolio. As the true market portfolio is unobserved, it is most of the time proxied by an index. Surprisingly only a few studies have considered the cross-section of corporate bond returns and their exposure to common risk 
factors. In the stock market literature, a typical risk factor is the aggregate market return, usually proxied by a market index such as the S\&P 500. In the corporate bond literature, the empirical studies usually do not consider any aggregate market return. Fama and French (1993) introduce the term structure factors as important risk factors in the cross-section of corporate bond returns. Later studies rely on these term and default factors, eventually introducing liquidity as an additional risk factor (Gebhardt et al., 2005, Lin et al., 2011, Acharya et al., 2013). The literature on corporate bonds disregards the pricing of a corporate bond market index in the cross-section of expected corporate bond returns. In this paper we use our newly-developed corporate bond price index to assess its explanatory power for individual corporate bond returns. In particular, we show that beyond the standard term, default and liquidity factors, this corporate bond market index is able to explain a significant fraction of the variation in corporate bond returns.

The paper is organised as follows. In the next section we review the literature on repeat-sales indices and on their performance assessment in the real estate market. Section 3 introduces the index methodology and the dataset. The performance tests that we apply to evaluate the accuracy of the index are described in Section 4. Finally, in Section 5 we assess the pricing of the index as a systematic risk factor. Section 6 concludes.

\section{Literature review}

Repeat-sales indices are very popular in the real estate literature. Initially developed by Bailey et al. (1963), the index is constructed based on observations of repeat sales of houses. No more than two transactions are required to be able to estimate an index, which makes it one of its strengths. The index construction has subsequently been modified by Case and Shiller (1987) to include the information related to the time interval of a repeat sale, in the sense that over longer trade intervals price changes are more likely to be induced by house-specific changes than by common market forces. The methodology has been widely adopted and is currently used by Standard\&Poor's and by the Federal Housing Finance Agency to provide official real estate indices in the US. We argue in this paper that this repeatsales technique provides an interesting approach to model corporate bond indices. Indeed we identify some important similarities between the two markets that allow us to draw the parallel to the housing market. First, 
houses are very heterogeneous assets, every house is unique because of its location, its size, its characteristics, etc. The same applies to bonds: due to different indentures and different issuers, they are never identical. Second, house sales are very infrequent and the average time between two house sales in the US is of the order of six years (Bollerslev et al., 2015). Even if the trading frequency of bonds is not to be compared to the one of houses, it is evident that for instance in contrast to the stock market, bonds trade relatively infrequently. In addition, this index procedure is a useful tool when it comes to the estimation of transaction costs on the corporate bond market. For instance, Harris and Piwowar (2006) and Edwards et al. (2007) model individual returns as a function of an aggregate index return and several sub-indices returns. The estimation of those indices is precisely done via a repeat-sales regression, but without any special emphasis on the technique. Wilkoff (2013) creates and analyses indices by rating, maturity, insurance status and additional bond characteristics for the US municipal bond market. He finds a correlation of around 0.8 between the repeatsales index and other existing indices. Spiegel and Starks (2016) analyse institutional rigidities emerging in the US corporate bond market around the downgrade from investment grade to high yield, and use a repeat-sales regression to construct their benchmark index. Bongaerts et al. (2011) use the repeat-sales method to construct portfolio returns of CDS contracts.

Since the application of repeat-sales indices to the corporate bond market is rather novel, no accuracy tests of the index technique have been carried out yet. We propose to transpose some of the techniques developed in the housing market to select an accurate technique among various existing repeatsales estimation procedures. Several papers have questioned and assessed the validity of repeat-sales regressions in the housing market. Goetzmann (1992) compares seven estimation techniques of repeat-sales indices to a reference series built from randomly selected NYSE data. The assessment of each method follows from the $\mathrm{R}^{2}$ and mean squared error criteria. The author finds that when the number of repeat-sales observations is large relative to the number of intervals estimated, the methodologies all perform well. However once this number is low a Bayesian estimation is privileged by the author. Crone and Voith (1992) similarly compare five parametric and non-parametric estimation methods of house price appreciation. The comparison is based on the mean squared error and on the mean absolute error of the prediction of known appreciation rates. They make a clear distinction between the efficiency gain stemming from the estimation method 
and the one from changing the sample size. Parametric methods are found to be superior in terms of accuracy and when the mean absolute prediction error is used as the selection criterion, the repeat-sales estimator is selected as the most accurate one. Repeat-sales estimates are similarly compared to a reference price index in Hill et al. (1997) through the computation of a loss function (mean squared error). In contrast to analysing the statistical properties of the estimator, Wang and Zorn (1997) focus on the target, hence the population measure that the index should meet, and on a method that should be chosen in accordance with this target. Their conclusion is that much of the debate over the index methodology is reduced to a disagreement on the desired target or the intended application. In this paper we essentially follow the approach in Goetzmann (1992) by building a reference series on a dataset and by assessing the ability of repeat-sales regressions to approximate the reference series. In line with Crone and Voith (1992), we take two perspectives for those tests: first we evaluate the recommended sample size to obtain the index and second we assess which technique and estimation procedure are optimal.

\section{Index methodology and data}

\subsection{Index construction}

In this section we outline the basic principle behind the index construction and we describe its several forms. There is a distinction between arithmetic and geometric indices. Early versions of repeat-sales indices were built geometrically (see, among others, Bailey et al. (1963) or Case and Shiller (1989)), that is, using data on log prices, thereby producing log indices, whose antilogs are essentially geometric averages of prices. Arithmetic indices instead are based on price levels (see, e.g., Shiller (1991) or Standard\&Poor's (2014)) and can have a portfolio interpretation that is lacking for geometric indices. The S\&P/Case-Shiller Home Price Indices originated by Case and Shiller in the 1980's are at this time recognised as reliable means to measure housing price movements and therefore officially generated and published by S\&P Dow Jones Indices. In their methodology they also adopt the arithmetic estimation procedure. ${ }^{5}$ In this paper we base 
our analysis on arithmetic indices as they have received more attention in the literature.

The arithmetic repeat-sales index is based on a simple regression of previous prices on current prices. The regression coefficient can be seen as a discounting factor and its inverse provides the index value. In practice, all transactions of the dataset are considered as trade pairs (or repeat sales), where each pair has an opening and a closing date. The opening date is the date of the previous transaction on the bond and the closing date is the date of the current transaction. Similarly each pair is considered along with its opening and closing prices. Only adjacent pairs are considered. If a bond trades four times for instance, one does not consider the trading pair between the first and third trade. ${ }^{6}$ If there are $n$ transactions for one bond, the bond will have $(n-1)$ pairs or repeat sales. The pairs are used to construct the vector of dependent variables $Y$ and the matrix of independent variables $X$. A base period is further chosen usually being the first period of the sample. The $Y$ vector has a length of $n-1$ and contains the opening price of the pair if the latter was opened in the base period and is zero otherwise. The $X$ matrix has $n-1$ rows and $T-1$ columns, where $T$ corresponds to the number of periods in the sample. Each column of the $X$ matrix refers to one period of the sample, except for the base period. The elements of $X$ are either prices or zeros. The column corresponding to a period is filled with the negative of the opening price of a pair if the opening was recorded in this period. The column is filled with the closing price, if the pair was closed in this period. The arithmetic index is then defined as the reciprocal of the $\beta$ in the simple regression model, without constant: $Y=\beta X+U$, where $U$ is a vector of errors.

To be more explicit, we illustrate the methodology with a simple example below. Consider the following set of trading pairs on bonds A, B, C, D and $\mathrm{E}$ over four periods 0 - the base period -, 1, 2 and 3. The example is described in Table 1.

In this example, the $Y$ vector and $X$ matrix are constructed as follows: 
Table 1. The Table provides an illustration on how bond trades are organised as repeat-sales. Panel $A$ represents a set of bonds, labelled $A$ to $E$, which traded at different time periods at the illustrated price. Panel B shows how the trades are grouped into repeat-sales. Each line corresponds to one repeat sale and gives the opening period and price of the repeat sale as well as the closing period and price of the same repeat sale.

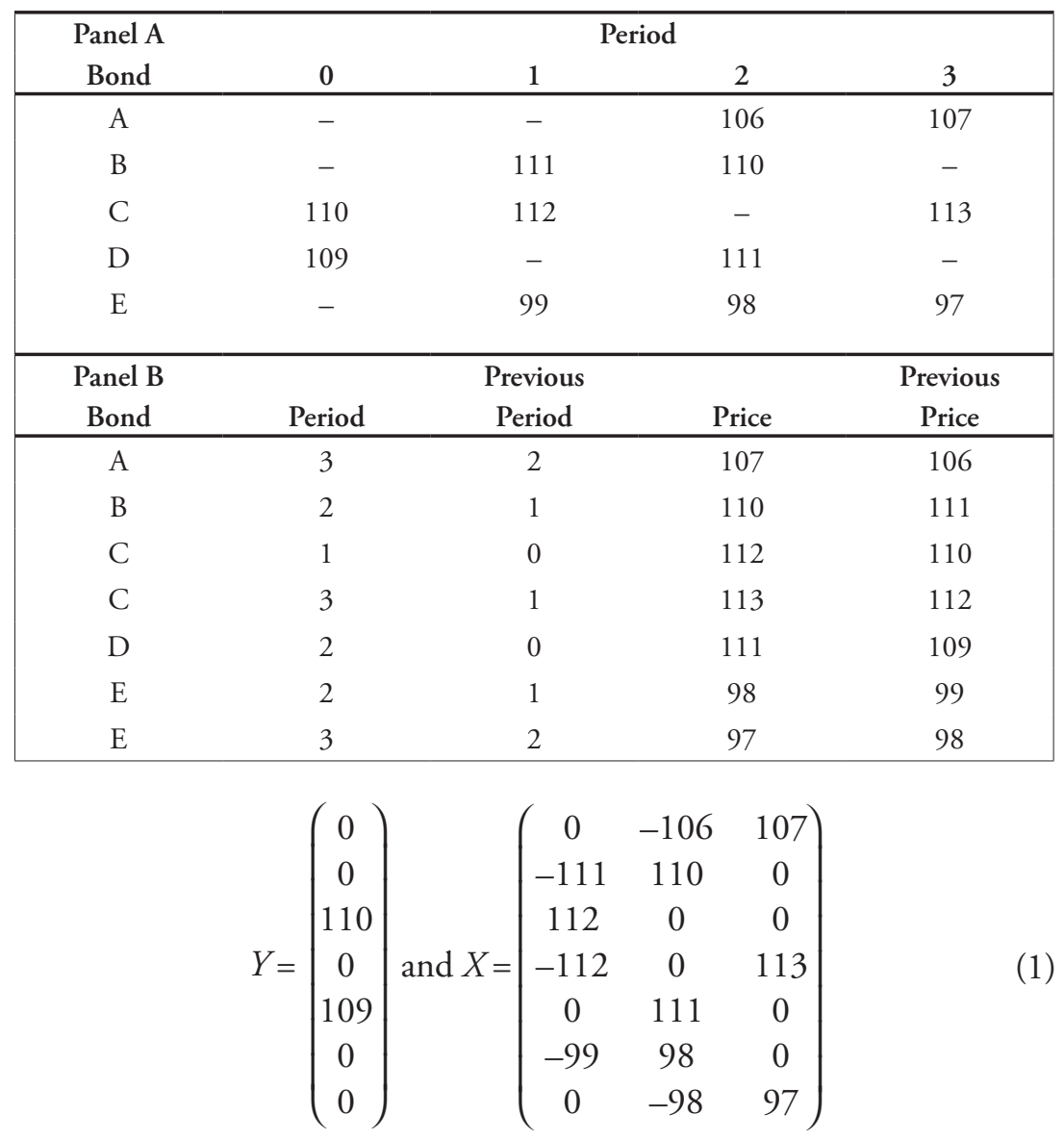

The $Y$ vector refers to the base period and contains the opening prices of trades opened in this period. The $X$ matrix contains three columns referring respectively to periods 1,2 and 3 . For each pair, the period-specific column contains the negative of the opening price if the pair was opened in this period and the closing price if the pair was closed in this period. Running the regression, we obtain the following coefficient vector $\beta^{\prime}=(0.98000 .9838$ 0.9788 ), where $\beta$ ' denotes the transposed $\beta$ vector. The index for the base 
period is one, while the index for the upcoming periods is obtained by simply taking the reciprocal of $\beta$ ', that is (1.0204 1.01641 .0216$)$.

As argued in the Standard\&Poor's (2014) home price index methodology some correlation might exist between the $X$ matrix and the error term $U$, because prices are measured with errors. They therefore recommend using an instrumental variables estimator given by $\beta^{\prime}=\left(Z^{\prime} X\right)^{-1} Z^{\prime} Y$ instead of the $\beta=\left(X^{\prime} X\right)^{-1} X^{\prime} Y$ of the linear model. The matrix $Z$ is obtained as $X$ exactly, where positive prices are replaced with 1 and negative prices with -1 . In our example $Z$ will look as follows:

$$
Z=\left(\begin{array}{ccc}
0 & -1 & 1 \\
-1 & 1 & 0 \\
1 & 0 & 0 \\
-1 & 0 & 1 \\
0 & 1 & 0 \\
-1 & 1 & 0 \\
0 & -1 & 1
\end{array}\right)
$$

By applying this instrumental variable estimation, we obtain the coefficient vector $\beta^{\prime}=(0.98010 .98400 .9795)$. The index for the base period is one, while the index for the upcoming periods is obtained by simply taking the reciprocal of $\beta^{\prime}$, that is, (1.0203 1.0162 1.0209).

In this specific setup the index also gets a conveniently intuitive interpretation, namely:

$$
\beta_{1}^{-1}=\frac{111+112+112+99}{\beta_{2} 110+110+\beta_{3} 113+\beta_{2} 98}
$$

and

$$
\beta_{2}^{-1}=\frac{106+110+111+98+98}{\beta_{3} 107+\beta_{1} 111+109+\beta_{1} 99+\beta_{3} 97}
$$

and

$$
\beta_{3}^{-1}=\frac{107+113+97}{\beta_{2} 106+\beta_{1} 112+\beta_{2} 98}
$$

The index value in a specific period is thus obtained as the ratio of current prices observed in this period and adjusted opening prices. These adjusted prices are simply the opening prices discounted back to the base period with their respective betas. Therefore in each period, the index is equal to the 
aggregate change in value of all bonds sold in that period with respect to the base period. This index is referred to as the value-weighted repeat-sales index.

The value-weighted index assumes that the error terms of each sales pair are identically distributed. However as argued by Case and Shiller (1987) and Standard\&Poor's (2014), the error variance might depend on the time interval between the sales in each pair. In the case of the housing market, if the sales pair has a longer time interval, the price changes are more likely to be driven by changes in the property itself than by changes in market value. To overcome this issue the index is estimated in three steps, taking into account the dependence between the variance of the error terms and the time interval of a sales pair. ${ }^{7}$ The first step is unchanged from above. The second step involves a regression of the residuals obtained in the first step on the time interval of each sales pair. Finally the third step uses the inverse of the fitted values of the regression in step two as weights to each sales pair. Those weights are used to build the diagonal elements of the matrix $\Omega$ and the interval-weighted index is then obtained as $\beta=\left(Z^{\prime} \Omega^{-1} X\right)^{-1} Z^{\prime} \Omega^{-1} Y$. Sales pairs with a longer time interval accordingly receive less weight in the index construction. Applying this specification yields a coefficient vector of $\beta^{\prime}=(0.98010 .98340 .9784)$ and index values of (1.0203 1.0168 1.0221).

We have described the index methodology of the arithmetic price index, which can be either value-weighted or interval-weighted. In practice, the estimation of the index can proceed in two ways. The standard procedure is to do a simultaneous estimation, where the regression is run with the entire $X$ matrix. Any estimated value of an index point is conditional on the estimated value of all other index points. To overcome this dependence on the one hand and to be able to estimate the index on long time series at a higher frequency (for instance daily) on the other hand, a chain-weighting procedure has been introduced by Shiller (1991) and is further described in Standard\&Poor's (2014) or Bollerslev et al. (2015). In this chain-weighting procedure, the same regressions are used but index values are conditioned only on past values of the index, that is, treating them as known before the estimation. First, the simultaneous method is used to estimate values during a starting period (for instance a year) and later values of the index are obtained by conditioning on those values and on all upcoming estimations. The value for a specific period is obtained by modifying the dependent

7. Details on the heteroskedastic variance structure of the errors are provided in Standard\&Poor's (2014). 
variable and by keeping only the independent variable, i.e. the column, related to the estimated period. The $X$ matrix (independent variables) is transformed into a vector by keeping only the column referring to this period. It still contains either prices or zeros depending on whether a pair was closed in that period or not. There is no indicator for pairs that were opened on that day, as the closing information of this pair is not known at the time of estimation. The modification of the dependent variable is obtained by replacing the value in $\mathrm{Y}$ by the opening price multiplied by its corresponding index value, that is, its value discounted to the base period.

Following the example above, if we want to estimate the value of the arithmetic index in period 2 with a chain-weighting procedure, hence conditional on the values in periods 0 and 1 , we will use the following matrices:

$$
Y=\left(\begin{array}{c}
0 \\
111 \times 0.9801 \\
110 \\
0 \\
109 \times 1 \\
99 \times 0.9801 \\
0
\end{array}\right) ; X=\left(\begin{array}{c}
0 \\
110 \\
0 \\
0 \\
111 \\
98 \\
0
\end{array}\right) \text { and } Z=\left(\begin{array}{l}
0 \\
1 \\
0 \\
0 \\
1 \\
1 \\
0
\end{array}\right)
$$

The chain-weighting procedure yields an index estimate in period 2 of 1.0134. The intuitive interpretation of the arithmetic index is still maintained, as trades closed in the estimation period are found at the numerator and their 'discounted-to-the-base-period' price at the denominator:

$$
\beta_{2}^{-1}=\frac{110+111+98}{\beta_{1} 111+109+\beta_{1} 99}
$$

As we can see the index estimate of period 2 is now conditional only on the two previous periods but is no longer dependent on posterior index estimates.

\subsection{Bond transactions and characteristics}

We use the entire universe of corporate bond trades disseminated by TRACE. The database has progressively become the reference for studies on the US corporate bond market activity. It has been established in July 2002 
by the Financial Industry Regulatory Authority (FINRA) to facilitate the reporting of over-the-counter secondary market transactions in eligible fixed income securities. All brokers/dealers who are FINRA member firms have an obligation to report their transactions in corporate bonds to the system. While in its early years the database only covered bonds above a specific trade size and issuance threshold, it now covers around $99 \%$ of all transactions in the market.

As the database is composed of individual entries of many agents, it is open to potential recording errors which, if not appropriately accounted for, might bias the results considerably. We thus follow Dick-Nielsen (2009) for a thorough cleaning of the dataset. We delete true duplicates, reversals and account for same-day corrections. These records are identified via their trade status and an original message sequence number. Even if the problem of price outliers is somewhat mitigated by the set-up of the TRACE database itself, there is a need for a price sequence filter. Again, we follow Dick-Nielsen (2009) in the definition of our price outliers. An observation is defined as an outlier if its price is less than $\$ 1$ or greater than $\$ 500$, if it is more than $20 \%$ away from the median price in a day or from its previous trading price. The database also contains agency transactions, occurring when a dealer does not have a bond in her own inventory and needs to buy it from another dealer before selling it to her customer. We treat these agency transactions by only keeping one of the corresponding reported records.

We start the data collection in January 2004. We obtain a sample of $14,165,694$ observations on 82,571 unique issues over a period of eleven years, from January 2004 to December 2014. We further remove all trades that were registered during weekends or public holidays. For the purpose of our study we aggregate the data at a monthly frequency. For each bond in the database, we retain the last reported price of the month.

In Table 2, we show the distribution of the number of trades and trading days per bond in each year. The reported statistics give a picture of the - on average - low trading frequency but also huge disparity in trading activity in the cross-section of corporate bonds. The median number of trades remains relatively low, ranging from 23 trades per bond in 2004 to 36 trades per bond in 2014 with a peak at 49 trades in 2009. In most of the years, 25\% of the bonds trade less than 10 times a year. The total number of trades per bond can nevertheless increase markedly as is evidenced by the Max column. 
Table 2. The Table provides summary statistics on the trading frequency of corporate bonds in TRACE. It reports summary statistics on the distribution of the number of trades per bond during a year and the number of trading days for a bond during a year. It further shows the number of unique bonds (as identifed by their CUSIP) observed during a year and the percentage thereof that traded on less than 5 business days during a year. The distribution statistics are provided for 82,571 unique bonds contained in the database over the period from January 2004 to December 2014.

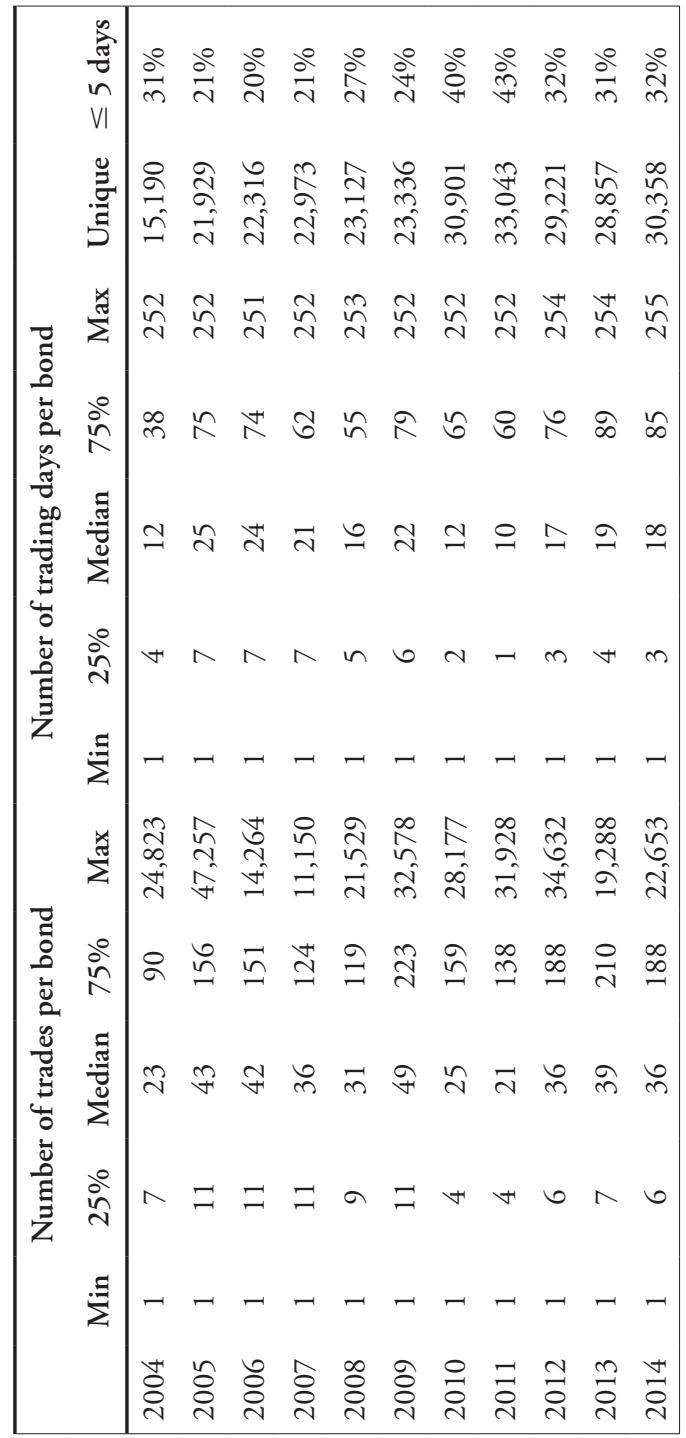


In terms of trading days per bond we observe that $25 \%$ of the bonds trade on less than 8 business days during a year, while $50 \%$ of the bonds only attain 25 days, in the best case (in 2005). However as shown in the Max column, there are nevertheless bonds trading on every business day. The overall pattern of these figures shows a steady increase in the trading activity of these bonds during the early years of the sample, which drops in 2008. The number of unique bonds covered in the database increases over the years, with a peak in 2011. This phenomenon is evidence of increased bond issuance activity but also reflects the gradual application of the reporting requirements to a larger set of bonds.

We further obtain the characteristics of these bonds from Mergent's FISD bondviewer database. Out of the 82,571 unique bonds of our initial sample, 69,691 bonds have their characteristics available in the Mergent database. We specifically extract information on the rating of the bond, provided by three rating agencies (Moody's, Fitch, Standard and Poor's), the maturity, the issue date, the coupon rate and the coupon frequency of the bond.

\section{Repeat-sales index performance}

In the literature, a number of papers has documented the superior performance of repeat-sales methods in the presence of incomplete price records (see, e.g., Crone and Voith (1992) or Goetzmann (1992) for the housing market). Due to the heterogeneous nature and to the irregular transaction frequency of the securities traded in the corporate bond market, we assess the ability of repeat-sales indices to accurately approximate the dynamics of this market.

Before constructing the index on the entire dataset we need to select an index construction and estimation method. Three estimators are considered: the value-weighted (hereafter RPS (I1)) or interval-weighted (RPS (I2)) arithmetic price index estimated simultaneously or the value-weighted price index estimated with a chain-weighting procedure (RPS (I3)). We assess their performance over the arithmetic mean of the prices in each period. When few observations are available, the standard choice to aggregate series is to use the arithmetic mean. We show in this paper that a repeat-sales procedure should be preferred. First, our goal is to find out which of the various repeat-sales estimators relative to the arithmetic average best proxies for the true index when trades are infrequent, that is, when bonds have unobserved 
prices over several periods. The selection is done by comparing the various estimates obtained from repeat-sales regressions to the arithmetic mean of prices. We then show which estimation method is best able to approximate a reference series based on absolute and relative performance measures. This approach as well as the construction of the reference series follows Goetzmann (1992). Working with NYSE data, the author computes the average of $\log$ prices over a set of 1,000 stocks for which a trade is observed daily. This daily average of log prices then provides an estimate of the 'true' index, which is compared to the estimates obtained on a sample where each stock has only one buy date and one sell date and where the index is estimated with a repeat-sales regression.

In the corporate bond market it is not possible to find any bond trading every day over the sample period considered in this paper. Contrary to NYSE stocks, bond transactions are far from being observed daily and it requires to put additional constraints on the dataset used for the accuracy assessment. We therefore choose to work at a monthly frequency. The first requirement in the construction of the reference series is to have a sample of bonds observed regularly over the entire sample period. We thus restrict the sample to those bonds that are traded every month over the sample period from February 2005 to December $2014 .{ }^{8}$ This leaves a set of 435 bonds for which we retain the last monthly transaction price. All accuracy tests are based on this restricted sample. The purpose of the tests is to find out which method out of an average price index or a repeat-sales procedure is more accurate in estimating the reference series based on the full dataset, once the dataset contains infrequent price observations. As long as the dataset is complete, that is, when it includes one observation per month for each bond, taking the average of available prices or estimating the price index with a repeat-sales method yields the same result. Once, as in the actual dataset, transactions are observed irregularly the methods however yield different results. We thus intend to find out which one should be preferred. First, the reference index series is obtained as the average of prices in each month, that is,

$$
I_{t}=\frac{1}{N} \sum_{i=1}^{N} P_{i, t}
$$

8. For the purpose of the simulation exercise, we use data as of February 2005. This date corresponds to the release of phase III of the system implementation, which was attained by gradually increasing the reporting requirements. As of this date, $99 \%$ of the transactions were reported. 
where $P_{i, t}$ is the closing price of bond $i$ in month $t$ and $N$ is the number of bonds in the complete dataset, i.e. 435 .

Second, we draw randomly in this dataset and retain only a few number of monthly observations. For each bond, $n$ monthly observations are selected, where $n=4, \ldots 50$, out of the 119 months available in the sample period. As a result a bond has $n-1$ repeat-sales pairs. We stop at 50 because as the performance tests show, the increased performance is negligible for larger numbers of observations. Furthermore, in practice, it would make little sense to require at least 50 bond transaction observations over a time of 119 periods. Given the low trading frequency almost no bond would indeed satisfy this criterion. For any $n$ we randomly select this number of transactions out of the 119 available observations for each bond. This entire procedure is repeated 100 times to obtain 100 different replications with observation numbers ranging from 4 to $50 .{ }^{9}$ The individual bond data is then aggregated to a price index by applying the repeat-sales procedures (value- or interval-weighted index estimated simultaneously or value-weighted index with a chain-weighted estimation). Those repeat-sales methods are then compared to the estimation obtained from taking the cross-sectional mean of the available prices in each month in the sample containing $n$ monthly observations per bond. For the repeat-sales regression to be valuable, we expect to obtain a better approximation of the reference series with a repeat-sales index as compared to the mean. Further we also wish to identify which one of the three available repeat-sales estimations should be preferred. Figure 1 provides plots of all methods when the number of observations varies between 5, 20, 35 and 50 monthly observations, along with the reference index series. It illustrates the 2.5 and 97.5 percentiles of the index values across the 100 replications. As the Figure suggests, while all index estimates converge towards their reference value as the number of observations increases, the arithmetic mean price index nevertheless appears more dispersed than its repeat-sales alternatives.

9. It is indeed not possible to estimate the chain-weighted index with two or three monthly observations per bond. All subsequent tests are therefore reported for 4 to 50 monthly observations, which amounts to a total of 4,700 alternative samples considered in our simulations. 
Figure 1. The Figure shows the 2.5 and 97.5 percentiles across the 100 replications of the index estimation over different numbers of observations. Estimations are obtained with 5, 20, 35 and 50 monthly observations per bond. The various index estimation techniques are the arithmetic mean, the value- or interval- weighted simultaneous estimation and the chain-weighted estimation. The estimations are based on a sample of 435 bonds which display an observation each month over the sample period from February 2005 to December 2014.
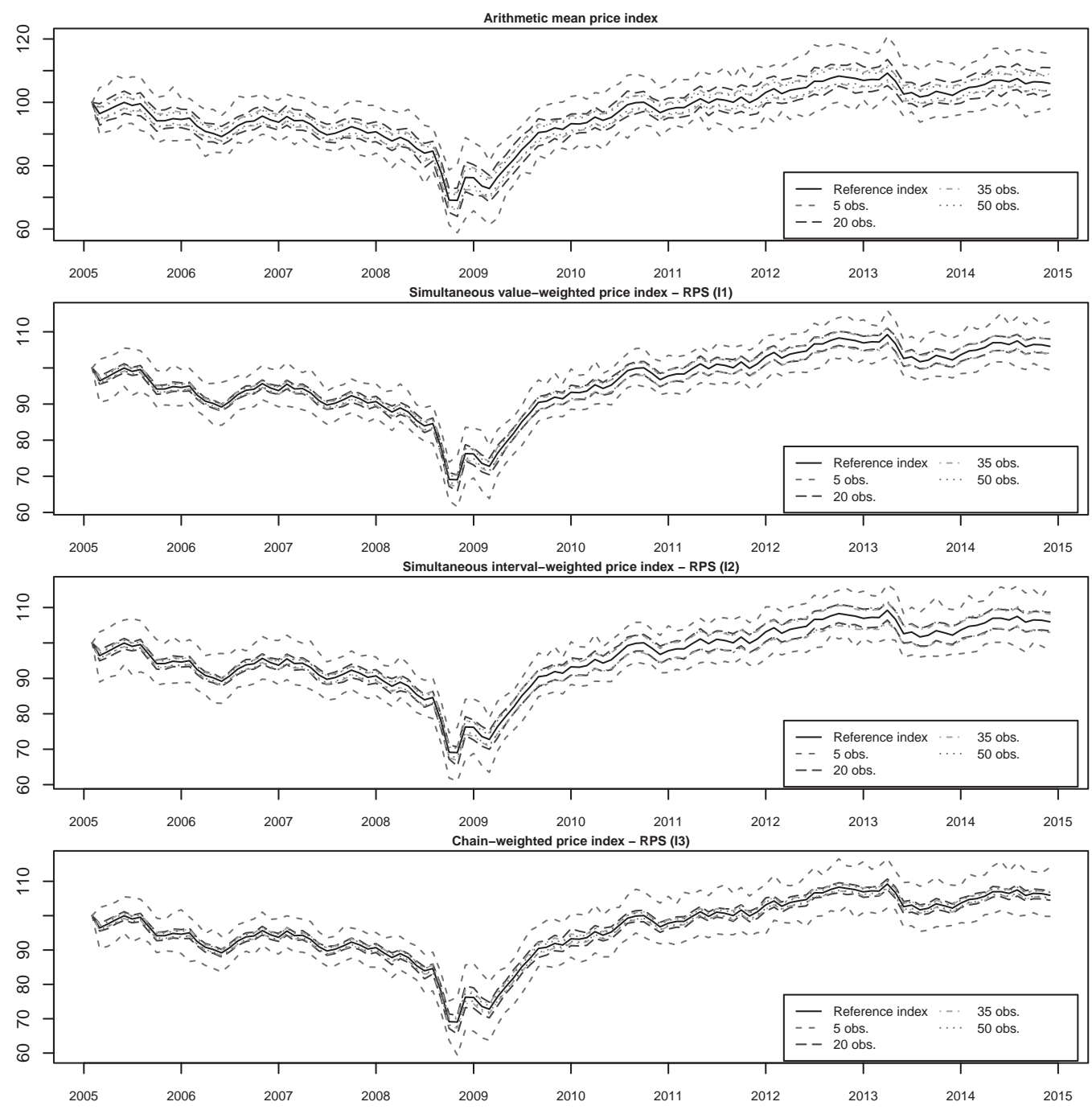


\subsection{Absolute performance of repeat-sales indices}

In a horse race, we examine the ability of our indices estimated from incomplete data to approximate the dynamics of our reference price index. We rely on the average loss between our index estimates and the reference index as an indicator of absolute index performance: the average loss will be lower for more accurate index approximations. As in Beaupain and Durré (2011), the robustness of our findings is assessed through alternative loss definitions: (a) the root mean squared error (RMSE), (b) the root mean squared proportional error (RMSPE), (c) the mean absolute error (MAE), (d) the mean absolute proportional error (MAPE), (e) the adjusted mean absolute proportional error (AMAPE) and (f) a quasi-likelihood loss function (QLIKE).

$$
\begin{array}{ll}
\text { RMSE }: & L_{n}^{\text {RMSE }}=\sqrt{1 / T \sum_{t=1}^{T}\left(I_{t}-I_{n, t}^{*}\right)^{2}} \\
\text { RMSPE }: & L_{n}^{\text {RMSPE }}=\sqrt{1 / T \sum_{t=1}^{T}\left[\left(I_{t}-I_{n, t}^{*}\right) / I_{n, t}^{*}\right]^{2}} \\
\text { MAE }: & L_{n}^{M A E}=1 / T \sum_{t=1}^{T}\left|I_{t}-I_{n, t}^{*}\right| \\
\text { MAPE }: & L_{n}^{\text {MAPE }}=1 / T \sum_{t=1}^{T}\left|\left(I_{t}-I_{n, t}^{*}\right) / I_{n, t}^{*}\right| \\
\text { AMAPE }: & L_{n}^{\text {AMAPE }}=1 / T \sum_{t=1}^{T}\left|\left(I_{t}-I_{n, t}^{*}\right) /\left(I_{t}+I_{n, t}^{*}\right)\right| \\
\text { QLIKE }: & L_{n}^{\text {QLIKE }}=1 / T \sum_{t=1}^{T}\left[\log \left(I_{n, t}^{*}\right)+\left(I_{t} / I_{n, t}^{*}\right)\right]
\end{array}
$$

where $I_{t}$ is the value of the reference price index at time $t$ computed as the average price in the complete dataset and $I_{n, t}^{*}$ is the index approximation for period $t$ estimated from an incomplete dataset composed of $n$ monthly observations randomly drawn from the complete dataset. ${ }^{10}$ To ensure comparability, all indices are re-based to 100 in the first month of our sample period. Figure 2 shows the average losses of our index estimators across 100 replications. The horizontal axis denotes the number of observations $(n)$ taken into consideration in our computations and goes from 4 to 50 observations. As the Figure shows, all alternative index estimators generally converge towards the reference price index as the number of repeat sales increases: losses are generally smaller as $n$ increases. In the presence of incomplete data, repeat-sales index estimates more closely approximate the reference price index than an average price index. The average losses of the repeat-sales indices are always under their mean price equivalent. 
Figure 2. The Figure shows the losses of the various index estimates with respect to the reference index series. We report six types of losses: RMSE, RMSPE, MAE, MAPE, AMAPE and QLIKE. The losses of each index estimate are averaged over 100 different replications. Each replication is based on a dataset of 435 bonds, which all have regular monthly observations over the period from February 2005 to December 2014. In each replication, a varying number of monthly observations is drawn, ranging from 4 to 50 monthly observations. Mean price is the index estimate obtained by averaging the available prices in a period, RPS (I1) is the value-weighted simultaneous index estimate, RPS (I2) is the interval-weighted simultaneous index estimate and RPS (I3) is the chain-weighted index estimate.
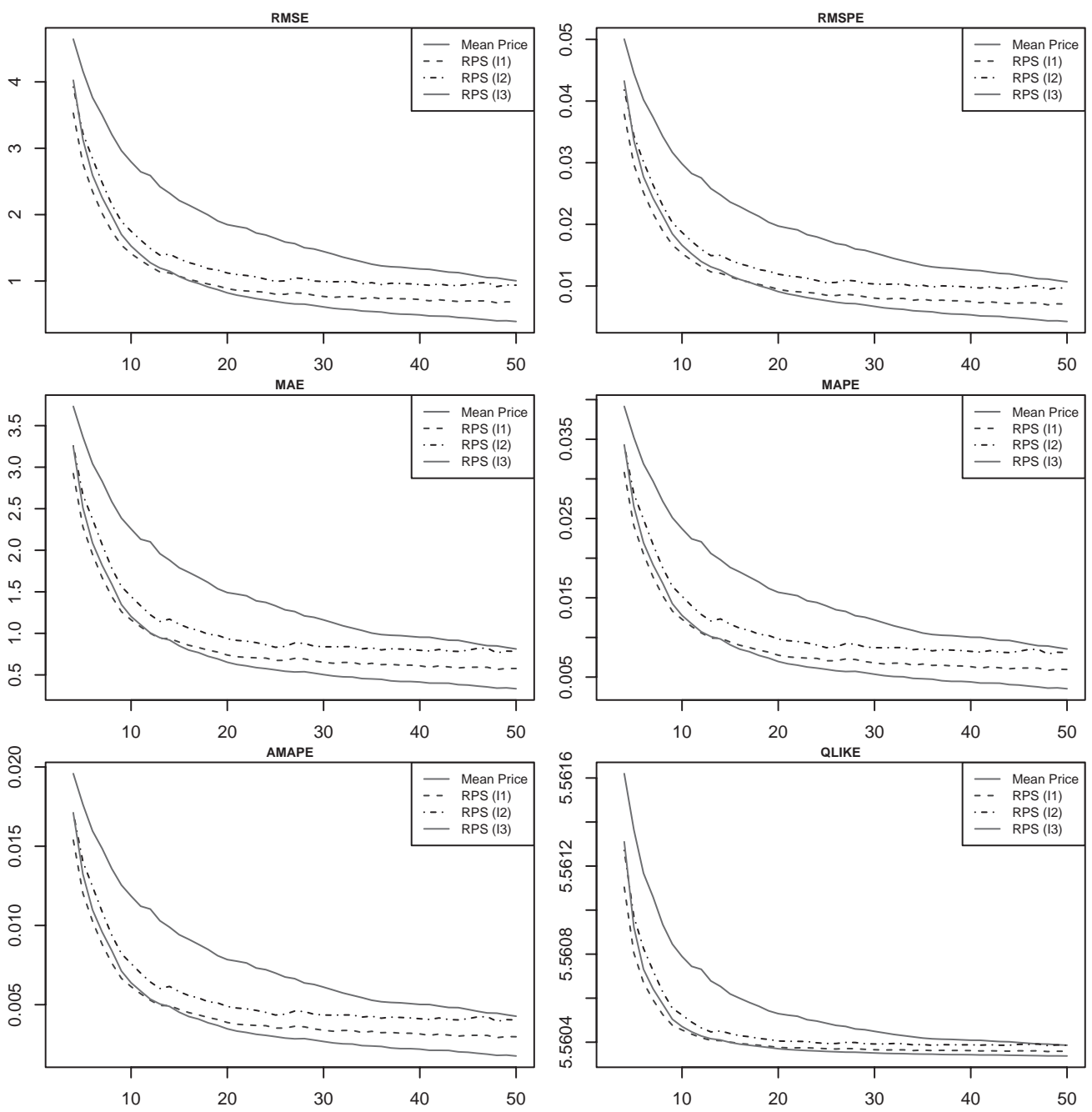
This result is insensitive to the composition of the incomplete dataset: specifically, it is not affected by the number of included observations. Among the repeat-sales estimators, the chain-weighting method (RPS (I3)) rapidly shows a superior performance: the method generates losses that are markedly below other repeat-sales alternatives when 17 or more observations are included in the computation. ${ }^{11}$ Interestingly, our results fail to support the superior performance of the interval-weighted repeat-sales technique (RPS (I2)), which generates larger losses than a simple one-step simultaneous estimate (RPS (I1)). This picture holds true across alternative loss definitions.

As in Goetzmann (1992), the absolute performance of our index estimators is further examined in a series of Mincer and Zarnowitz (1969) regressions, where the reference price index is regressed against each alternative index estimate $I_{n, t}^{*}$. In contrast to Goetzmann (1992), we also assess the sensitivity of our findings to the number of repeat-sales included in our index approximations. Increasing the number of sales pairs makes the dataset more complete and is therefore expected to yield more precise index estimates. In our Mincer and Zarnowitz (1969) regressions, we accordingly allow $n$ to take values going from 4 to 50 observations:

$$
I_{t}=\alpha+\gamma I_{n, t}^{*}+\varepsilon_{t}
$$

As the accuracy of an index approximation increases, the intercept of the regression $(\alpha)$ and the slope coefficient $(\gamma)$ are respectively expected to converge towards 0 and 1 . Perfect approximations would lead to an estimated intercept of 0 and a slope of 1 . By the same token, the $\mathrm{R}^{2}$ of the regression shows the proportion of the variance of the reference price index that is explained by its proxy. Figure 3 reports the intercept, slope coefficient and adjusted $R^{2}$ from our Mincer and Zarnowitz (1969) regressions. The horizontal axis denotes the number of observations included in the incomplete datasets. Numerical values for these parameters are also reported for a selection of sales pairs numbers included in the computation of our alternative index approximations in Table 3. Overall, our results lend further support to our initial findings. First, increasing the number of observations leads to more accurate index estimates: while intercepts and slope coefficients of each alternative index approximation converge towards their expected values as $n$ increases, the regression $\mathrm{R}^{2}$ rapidly stabilises at levels above 0.99 .

11. The chain-weighting method already outperforms other repeat-sales methods with 14 (under MAE, MAPE and AMAPE losses) or 15 (RMSE and QLIKE losses) observations. 
Second, our regressions confirm the superior performance of the repeat-sales methods to approximate the dynamics of the corporate bond market relative to mean price indices. This last finding appears in line with the evidence reported in Goetzmann (1992) for the housing market.

Figure 3. The Figure shows results of the Mincer and Zarnowitz (1969) regressions. The reference series is regressed on each estimated index and we report the alpha, gamma and $\mathrm{R}^{2}$ of the regression. These statistics are averaged over 100 different replications. Each replication is based on a dataset of 435 bonds, which all have regular monthly observations over the period from February 2005 to December 2014. In each replication, a varying number of monthly observations is drawn, ranging from 4 to 50 monthly observations. Mean price is the index estimate obtained by averaging the available prices in a period, RPS (I1) is the value-weighted simultaneous index estimate, RPS (I2) is the interval-weighted simultaneous index estimate and RPS (I3) is the chain-weighted index estimate.
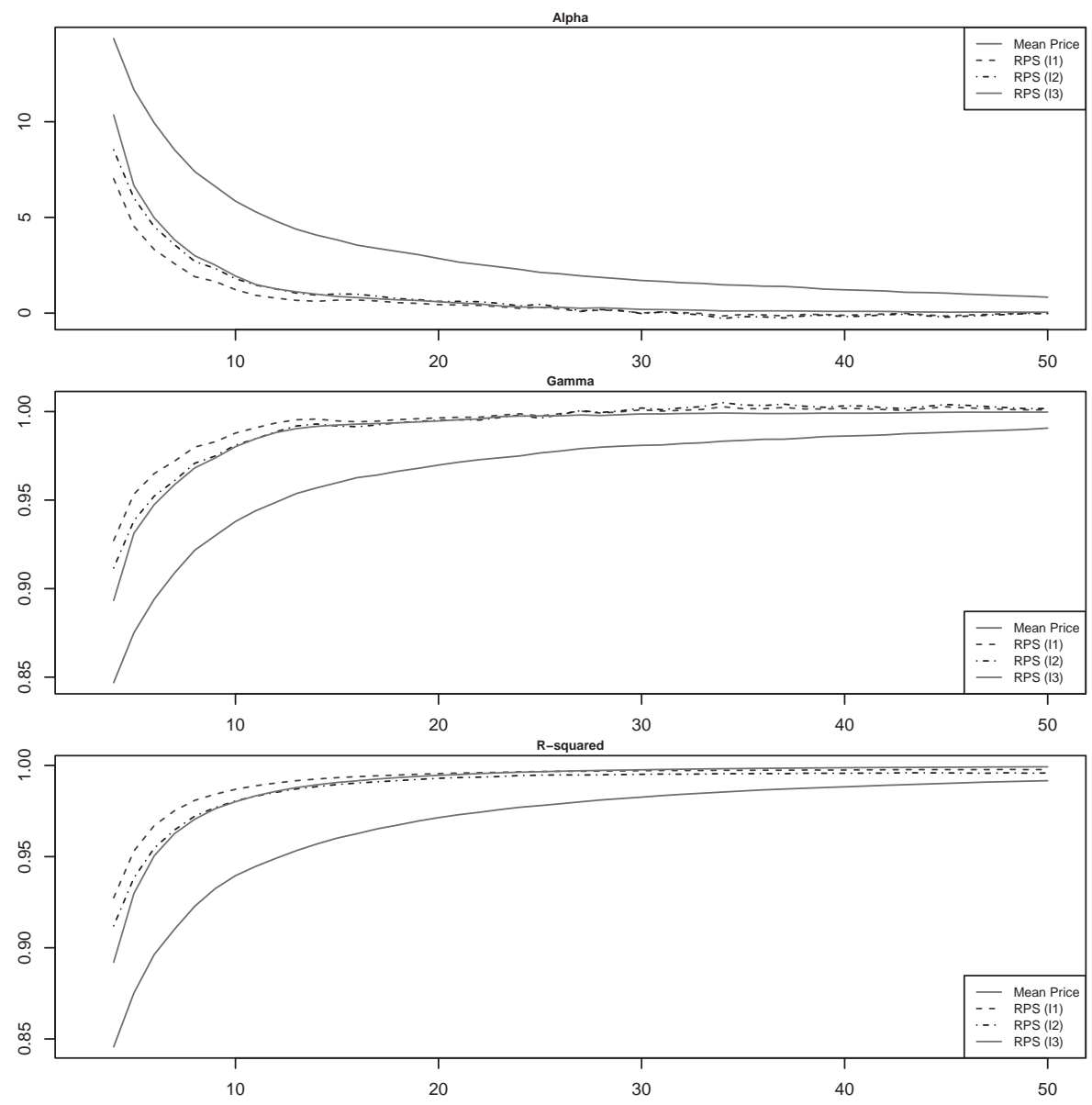
Table 3. The Table provides results of the Mincer and Zarnowitz (1969) regressions. The reference series is regressed on each estimated index and we report the alpha, gamma and $\mathrm{R}^{2}$ of the regression. These statistics are averaged over 100 different replications. Each replication is based on a dataset of 435 bonds, which all have regular monthly observations over the period from February 2005 to December 2014. In each replication, a varying number of monthly observations is drawn, ranging from 4 to 50 monthly observations. Mean Price is the index estimate obtained by averaging the available prices in a period, RPS (I1) is the value-weighted simultaneous index estimate, RPS (I2) is the interval-weighted simultaneous index estimate and RPS (I3) is the chain-weighted index estimate.

\begin{tabular}{|c|c|c|c|c|c|c|c|c|}
\hline & \multicolumn{4}{|c|}{ Alpha } & \multicolumn{4}{|c|}{ Gamma } \\
\hline $\begin{array}{c}\text { Number } \\
\text { of obs. }\end{array}$ & $\begin{array}{c}\text { Mean } \\
\text { Price }\end{array}$ & $\begin{array}{l}\text { RPS } \\
\text { (I1) }\end{array}$ & $\begin{array}{c}\text { RPS } \\
\text { (I2) }\end{array}$ & $\begin{array}{c}\text { RPS } \\
\text { (I3) }\end{array}$ & $\begin{array}{c}\text { Mean } \\
\text { Price }\end{array}$ & $\begin{array}{l}\text { RPS } \\
\text { (I1) }\end{array}$ & $\begin{array}{c}\text { RPS } \\
\text { (I2) }\end{array}$ & $\begin{array}{l}\text { RPS } \\
\text { (I3) }\end{array}$ \\
\hline 5 & 11.671 & 4.535 & 6.008 & 6.657 & 0.875 & 0.953 & 0.938 & 0.931 \\
\hline $6-10$ & 7.665 & 2.138 & 2.984 & 3.250 & 0.918 & 0.978 & 0.968 & 0.966 \\
\hline $11-15$ & 4.476 & 0.735 & 1.142 & 1.146 & 0.953 & 0.994 & 0.990 & 0.989 \\
\hline $16-20$ & 3.212 & 0.563 & 0.789 & 0.702 & 0.966 & 0.995 & 0.993 & 0.994 \\
\hline $21-30$ & 2.139 & 0.230 & 0.328 & 0.328 & 0.977 & 0.999 & 0.998 & 0.997 \\
\hline $31-40$ & 1.434 & -0.064 & -0.141 & 0.124 & 0.984 & 1.002 & 1.003 & 0.999 \\
\hline \multirow[t]{2}{*}{$41-50$} & 1.013 & -0.059 & -0.103 & 0.060 & 0.988 & 1.001 & 1.003 & 0.999 \\
\hline & \multicolumn{8}{|c|}{$\mathrm{R}^{2}$} \\
\hline $\begin{array}{c}\text { Number } \\
\text { of obs. }\end{array}$ & \multicolumn{2}{|c|}{ Mean Price } & \multicolumn{2}{|c|}{ RPS (I1) } & \multicolumn{2}{|c|}{ RPS (I2) } & \multicolumn{2}{|c|}{ RPS (I3) } \\
\hline 5 & \multicolumn{2}{|c|}{0.875} & \multicolumn{2}{|c|}{0.953} & \multicolumn{2}{|c|}{0.938} & \multicolumn{2}{|c|}{0.930} \\
\hline $6-10$ & \multicolumn{2}{|c|}{0.920} & \multicolumn{2}{|c|}{0.979} & \multicolumn{2}{|c|}{0.970} & \multicolumn{2}{|c|}{0.968} \\
\hline $11-15$ & \multicolumn{2}{|c|}{0.953} & \multicolumn{2}{|c|}{0.991} & \multicolumn{2}{|c|}{0.987} & \multicolumn{2}{|c|}{0.987} \\
\hline $16-20$ & \multicolumn{2}{|c|}{0.967} & \multicolumn{2}{|c|}{0.995} & \multicolumn{2}{|c|}{0.992} & \multicolumn{2}{|c|}{0.993} \\
\hline $21-30$ & \multicolumn{2}{|c|}{0.978} & \multicolumn{2}{|c|}{0.997} & \multicolumn{2}{|c|}{0.994} & \multicolumn{2}{|c|}{0.997} \\
\hline $31-40$ & \multicolumn{2}{|c|}{0.986} & \multicolumn{2}{|c|}{0.997} & \multicolumn{2}{|c|}{0.996} & \multicolumn{2}{|c|}{0.998} \\
\hline $41-50$ & \multicolumn{2}{|c|}{0.990} & \multicolumn{2}{|c|}{0.998} & \multicolumn{2}{|c|}{0.996} & \multicolumn{2}{|c|}{0.999} \\
\hline
\end{tabular}

\subsection{Relative performance of repeat-sales indices}

To confirm the superior performance of our repeat-sales index estimates relative to their mean price alternative, we further build a statistical test that compares their respective losses. Specifically, we compute a Diebold and Mariano (1995) test statistic from the loss differential between a repeat-sales index approximation and the mean price index. The test is constructed to examine the equality of the losses generated with a repeat-sales estimator relative to the losses of the mean price index. The test statistic accounts for 
potential autocorrelation of the loss differentials and is normally distributed. By design, a negative value for the Diebold and Mariano (1995) test statistic hints at the superior performance of the repeat-sales index over the mean-price index, that is, the losses implied by the mean price index exceed the losses observed for the repeat-sales approximation. The results are reported in Figure 4, which shows the average value of the test statistic for 100 replications with squared (SE), squared proportional (SPE), absolute (AE), absolute proportional (APE), adjusted absolute proportional (AAPE) and QLIKE errors. The horizontal axis denotes the number of monthly observations used for computing the value of each index approximation. ${ }^{12}$ Overall our results lend further statistical support to the superior performance of the repeat-sales indices for approximating the dynamics of the corporate bond market. Indeed, the Diebold and Mariano (1995) test statistic is negative for all loss definitions at every number of sales pairs included in the index approximation, confirming that, in the presence of incomplete price information, repeat-sales methods lead to smaller losses than a mean price index. Furthermore, the chain-weighting index estimation (RPS (I3)) rapidly emerges as a superior index estimate (relative to a mean price index): the associated test statistic is strongly significant for all values of $n$ and it remains markedly stable provided that at least 25 observations are included in the index estimate. Finally, our tests also support the superior performance of the one-step repeat-sales estimates (RPS (I1)) compared to its three-step equivalent (RPS (I2)): the statistical significance of the Diebold and Mariano (1995) test statistic is stronger for RPS (I1) than for RPS (I2). An examination of the proportion of significant test statistics (at the 1\%,5\% and 10\% level of significance) across the 100 replications reported in Figure 5 confirms the above findings. ${ }^{13}$ Specifically, in the cross-section of our replications, the chain-weighting method significantly outperforms the mean price index when at least 10 monthly observations are included in the computation and this superior performance remains stable as the number of repeat sales further increases.

12. Numerical values of the test statistic by observation numbers are available upon request.

13. For the sake of brevity, the proportion of significant tests reported in Figure 5 is based on a squared proportional errors (SPE) loss function. An examination of our alternative loss functions yields qualitatively similar conclusions. The results are available upon request. 
Figure 4. The Figure reports Diebold and Mariano (1995) test statistics on the relative accuracy of the different index proxies. The test statistic is obtained by comparing paired losses. We report six types of losses: squared errors (SE), squared proportional errors (SPE), absolute errors (AE), absolute proportional errors (APE), adjusted proportional errors (AAPE) and QLIKE. Each pair consists of the arithmetic mean of available prices and one of the repeat-sales index estimates. The loss differential of each pair is averaged over 100 different replications. Each replication is based on a dataset of 435 bonds, which all have regular monthly observations over the period from February 2005 to December 2014. In each replication, a varying number of monthly observations is drawn, ranging from 4 to 50 monthly observations. Mean price is the index estimate obtained by averaging the available prices in a period, RPS (11) is the value-weighted simultaneous index estimate, RPS (I2) is the interval-weighted simultaneous index estimate and RPS (I3) is the chain-weighted index estimate.
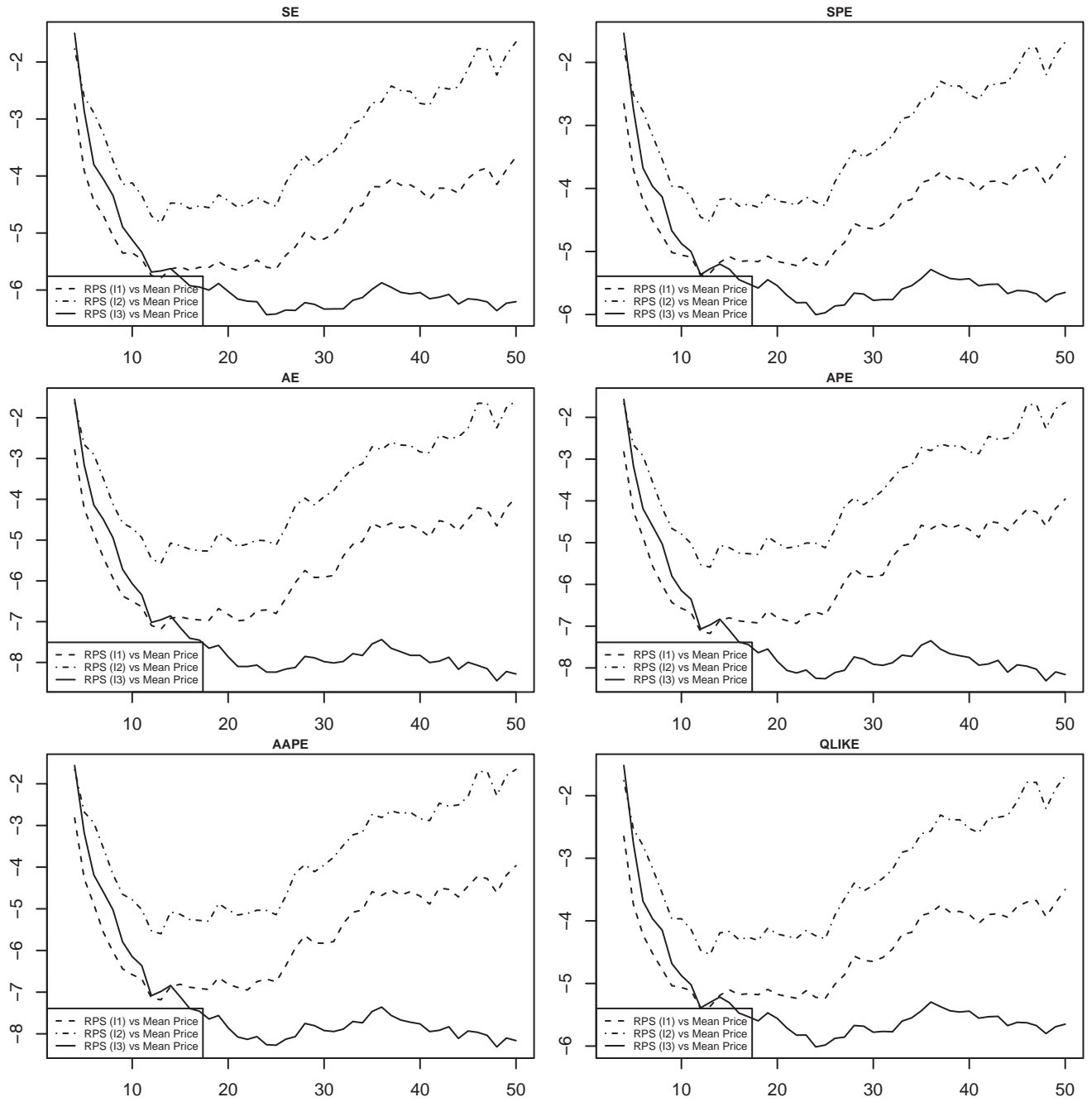
Figure 5. The Figure reports the percentage of significant Diebold and Mariano (1995) test statistics, at the $1 \%, 5 \%$ and $10 \%$ statistical significance level. The test statistic is obtained by comparing paired losses. The series are based on the squared proportional errors (SPE) loss. Each pair consists of the arithmetic mean of available prices and one of the repeat-sales index estimates. The percentage is obtained over 100 different replications. Each replication is based on a dataset of 435 bonds, which all have regular monthly observations over the period from February 2005 to December 2014. In each replication, a varying number of monthly observations is drawn, ranging from 4 to 50 monthly observations. Mean price is the index estimate obtained by averaging the available prices in a period, RPS (I1) is the value-weighted simultaneous index estimate, RPS (I2) is the interval-weighted simultaneous index estimate and RPS (I3) is the chain-weighted index estimate.
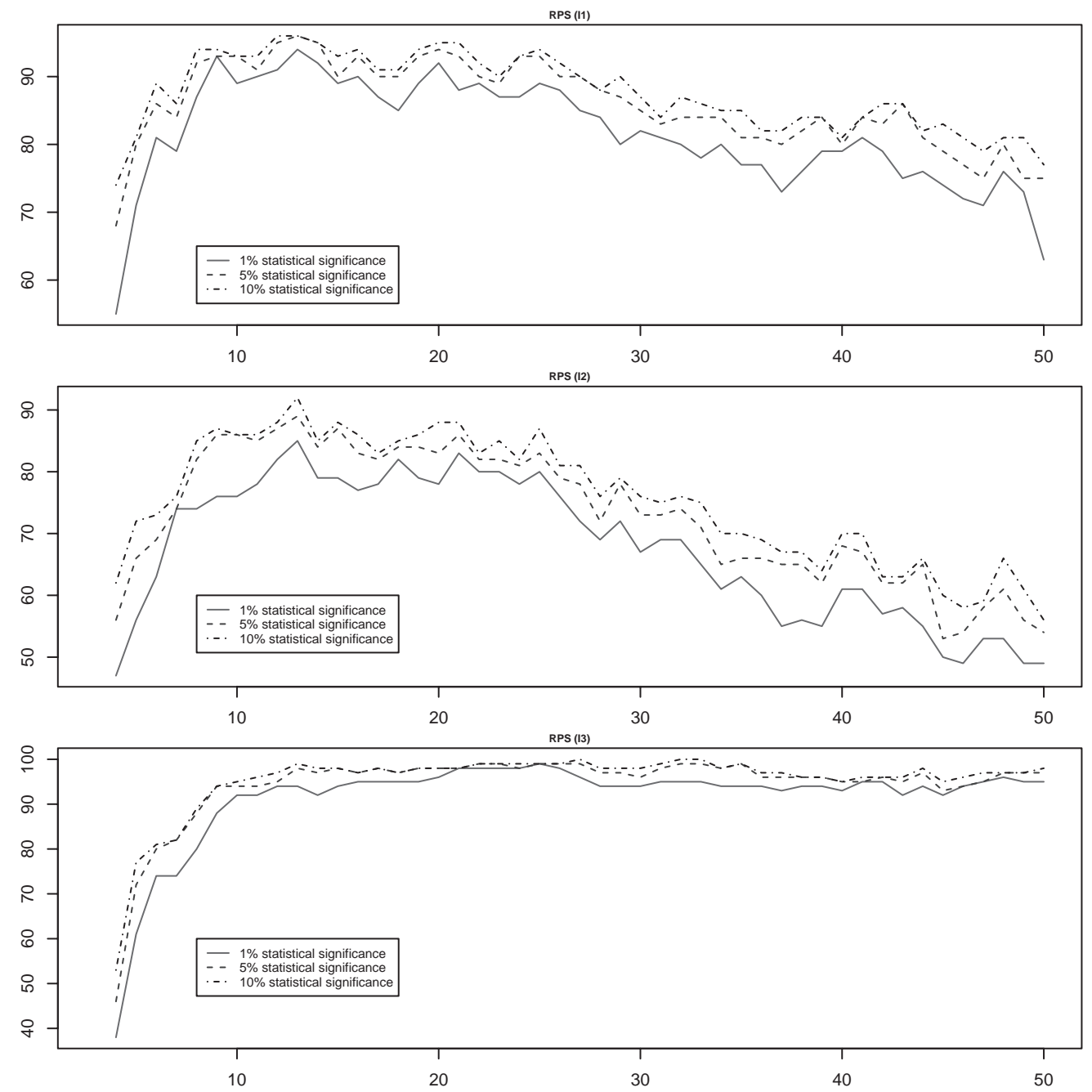
Our assessments of the absolute and of the relative index approximation performance therefore lead to similar conclusions: the repeat-sales methods first emerge as credible alternatives to mean price index estimates for the corporate bond market. Second, the chain-weighting method (RPS (I3)) rapidly stands as a superior index estimator in the specific context of incomplete price observations. Interestingly, the single-step simultaneous repeat-sales estimation method (RPS (I1)) almost always outperforms its three-step alternative (RPS (I2)): our tests indeed fail to provide empirical support in favour of an adjustment for the time between price observations in the corporate bond market.

\section{Explaining the cross-section of corporate bond returns with a repeat-sales price index}

In this section, we investigate whether a bond's return is related to systematic risk as proxied by a repeat-sales price index factor. This factor might be important beyond the typical term, default and liquidity factors that are priced in corporate bonds. In some studies, the Fama and French (1993) three factors (Market, SMB, HML) are included in the analysis, but with a market index still derived from stocks. Further these three factors do not significantly explain variations in bond returns as is found in Lin et al. (2011). Inspired by Lin et al. (2011) we adopt a factor model which includes the term, default and liquidity factors but does not include the stock market-related factors. Instead we use a bond-specific index constructed from a repeat-sales estimation, to capture the exposure to systematic market risk. The factor model can be represented as follows:

$$
r_{i, t}-r_{f, t}=\alpha_{i}+\beta_{i, M K T} M K T_{t}+\beta_{i, T E R M} T E R M_{t}+\beta_{i, D E F} D E F_{t}+\beta_{i, L I Q} L I Q_{t}+\varepsilon_{i, t}
$$

where the $\beta$ 's capture the exposure of individual bond excess returns to systematic risk factors as proxied by the bond market index return, the term and default premiums and a market-wide liquidity factor. The bond excess returns are obtained by subtracting the one-month risk-free interest rate as available in Kenneth French's data library from the individual bond return.

As shown in the previous section, a superior estimate of the bond market index is obtained from a chain-weighting estimation. As of 35 monthly observations per bond, the decrease in the absolute error when adding 
observations is negligible and our price index factor is therefore estimated on all bonds in the database with at least 35 monthly observations, over the period from January 2004 to December 2014. MKT is the excess return on the repeat-sales price index. TERM is the term premium and is constructed as the return difference between long-term Treasury bonds (30 years) and short-term Treasury bonds ( 2 years). It captures the risk associated with unexpected interest rate changes. DEF is the default premium and is constructed as the return difference between BofA Merrill Lynch's $\mathrm{BB}$ and $\mathrm{AAA}$ corporate bond indices. It captures the risk associated with unexpected changes in the credit quality of firms. ${ }^{14}$

The liquidity factor is constructed based on individual liquidity measures of all bonds available in the database. We use two standard liquidity measures available in the literature. The Amihud (2002) price impact ratio measures the impact on the price of a given trade size. It is obtained daily, for all bonds which have at least three daily observations (Maalaoui Chun et al., 2014, Dick-Nielsen et al., (2012):

$$
A m i_{i, t}=\frac{1}{N} \sum_{j=1}^{N} \frac{\left|\operatorname{return}_{j, t}^{i}\right|}{\operatorname{volume}_{j, t}^{i}}
$$

where $N$ is the number of returns during each day $t$, return $_{j, t}^{i}$ is the return on the $j$-th transaction during day $t$ and volume $_{j, t}^{i}$ is the volume of this $j$-th transaction. The value in the month is obtained as the average of daily values.

Further we construct another liquidity factor based on the imputed round-trip cost measure, which is specifically designed for the corporate bond market (Feldhütter, 2012). It is based on the observation that bonds might trade two or three times within a short interval, after a long interval without any trade. This is likely to occur because a dealer matches a buyer and a seller and collects the bid-ask spread as a fee. The dealer buys the bond from a seller, and further sells it to the buyer. The price difference can be seen as the transaction cost or the bid-ask spread. The imputed round-trip cost (IRC) is therefore defined as:

$$
I R C_{i, t}=\frac{P_{i, t}^{\max }-P_{i, t}^{\min }}{P_{i, t}^{\max }}
$$

14. The series used to construct the term factor were obtained from Bloomberg and the series used to construct the default factor were obtained from the Federal Reserve Bank of St. Louis. 
where $P_{i, t}^{\max }$ and $P_{i, t}^{\min }$ are the highest and lowest prices in the set of transactions with the same size, within a day. For each bond we obtain the daily IRC as the average of round-trip costs on that day for different sizes and we then take averages of daily estimates to obtain monthly estimates.

The market-wide liquidity factor $L I Q$ is then obtained by aggregating individual illiquidity measures of all bonds in the sample. We consider changes in market-wide liquidity by taking the first difference of the series.

The factor model is tested on a set of 16,213 bonds available in the TRACE database, selected based on their trading frequency. In line with the index construction procedure, we retain all bonds with 35 monthly observations or more for the cross-sectional tests. We use the bond's coupon rate and coupon frequency to calculate the monthly bond return:

$$
r_{t}=\frac{\left(P_{t}+A I_{t}\right)+C_{t}-\left(P_{t-1}+A I_{t-1}\right)}{P_{t-1}+A I_{t-1}}
$$

where $A I$ stands for accrued interest and $C$ for coupon payment.

We compute the correlations between the different explanatory variables as well as the variance inflation factor of each of them. While some correlation exists between the market index and the default factor or the IRC liquidity factor, the variance inflation factors of each explanatory variable are between 1.2 and 2.5 so that we do not face dramatic multicollinearity issues. $^{15}$

\subsection{Tests on individual bonds}

We start by estimating loadings on risk factors over the full period for which an individual bond is available in the sample. Table 4 provides summary statistics on the estimated loadings and on the percentage of bonds for which a specific risk factor is statistically significant. Panel A reports the results when the bond market index is not included in the regression. On average the bonds in the sample exhibit a positive exposure to term and default risk factors. The average exposure to the liquidity factor is negative, suggesting that liquidity shocks reduce bond returns. The factor loadings can be positive as well as negative, as evidenced by the minimum and maximum values. Default is the most important factor as it is statistically 
significant at the 5\% level for $43 \%$ (with Amihud) or 37\% (with IRC) of the bonds. Panel B reports the results when the repeat-sales bond market index is included in the regression. As evidenced by the coefficient values, the bond market index captures a significant fraction of the time series variation previously captured by other factors. The average sensitivity to the index return is positive but can range between large negative and positive values. It is highly explanatory for individual bond returns as it is statistically significant at the $5 \%$ level for $53 \%$ (IRC liquidity measure) to $57 \%$ (Amihud liquidity measure) of the bonds, which is a higher rate than for other factors. Adding the market index return as a factor considerably increases the adjusted $\mathrm{R}^{2}$ value (from $14 \%$ to $25 \%$ in case of the Amihud illiquidity measure and from $16 \%$ to $25 \%$ in case of the IRC measure).

We further study the cross-sectional exposure of individual bond returns to the factor loadings. Since the time-series of some bonds in the sample is rather short, it is not possible to estimate individual rolling-window betas. Instead we estimate the loadings in three sub-periods and we consider their explanatory power for the cross-section of individual bond returns. The monthly bond excess returns over the risk-free rate are averaged over the months in the period. To account for the financial crisis, we define period 1 from January 2004 to August 2008, period 2 from September 2008 to August 2010 (the crisis period) and period 3 from September 2010 to December 2014. Results are reported in Table 5. Individual bond returns appear to be significantly related to the bond market index, term, default and liquidity factors. Except for TERM, the explanatory power of the factors is also much higher in the first period than in other periods and the signs of the premiums change from one period to another. Exposure to market risk, as captured by the loading on the repeat-sales index return, is negatively priced in the first period and positively priced in the last period, while it does not require any premium during the crisis period. As a result of market risk, individual returns are reduced by 22 basis points in the first period and are higher by 9 to 11 basis points in the post-crisis period. The premium on other factors is changing over time and during the crisis period, exposure to term and liquidity factors require a positive premium. 
Table 4. The Table reports full-period estimates of betas associated with bond market return, term, default and liquidity factors. Panel A shows the results when the bond market return is omitted and panel B when it is included in the regression. MKT is the bond market index excess return obtained from a repeat-sales estimation over all bonds in the sample, with at least 35 monthly observations. TERM is the term premium constructed as the yield difference between long-term Treasury bonds and short-term Treasury notes. DEF is the default premium and is constructed as the return difference between BofA Merrill Lynch's BB and AAA corporate bond indices. Liquidity factors are obtained using either the Amihud illiquidity measure or the imputed round-trip cost. The Table reports distribution statistics of the betas obtained on the different factors and the percentage of bonds that exhibit significant coefficients at the $10 \%, 5 \%$ and $1 \%$ statistical signicance levels. The sample contains 16,213 individual bonds. All variables are constructed monthly and the period is from January 2004 to December 2014.

\begin{tabular}{|c|c|c|c|c|c|c|c|}
\hline \multicolumn{8}{|c|}{$\begin{array}{c}\text { Panel A: Without index factor } \\
\text { Amihud Liquidity }\end{array}$} \\
\hline Variable & Mean & Minimum & Maximum & s.d. & \%bonds ${ }_{10 \%}$ & \%bonds & $\%$ bonds ${ }_{1 \%}$ \\
\hline TERM & 0.12 & -7.51 & 6.70 & 0.37 & 0.43 & 0.35 & 0.28 \\
\hline DEF & 0.51 & -20.28 & 20.50 & 1.03 & 0.50 & 0.43 & 0.36 \\
\hline LIQ & -0.02 & -2.83 & 1.83 & 0.12 & 0.28 & 0.20 & 0.14 \\
\hline Adj. $\mathrm{R}^{2}$ & 0.14 & -0.16 & 0.82 & 0.15 & & & \\
\hline \multicolumn{8}{|c|}{ IRC Liquidity } \\
\hline Variable & Mean & Minimum & Maximum & s.d. & \%bonds ${ }_{10 \%}$ & \%bonds ${ }_{5 \%}$ & \%bonds \\
\hline TERM & 0.09 & -7.68 & 7.03 & 0.38 & 0.39 & 0.31 & 0.24 \\
\hline DEF & 0.43 & -16.10 & 22.41 & 0.97 & 0.44 & 0.37 & 0.30 \\
\hline LIQ & -28.10 & -1567.14 & 769.16 & 68.13 & 0.37 & 0.29 & 0.22 \\
\hline Adj. $R^{2}$ & 0.16 & -0.16 & 0.83 & 016 & & & \\
\hline \multicolumn{8}{|c|}{ Panel B: With index factor } \\
\hline \multicolumn{8}{|c|}{ Amihud Liquidity } \\
\hline MKT & 1.10 & -25.55 & 46.93 & 1.80 & 0.63 & 0.57 & 0.49 \\
\hline TERM & -0.04 & -9.56 & 6.17 & 0.42 & 0.27 & 0.20 & 0.13 \\
\hline DEF & 0.04 & -18.82 & 18.64 & 1.08 & 0.40 & 0.32 & 0.24 \\
\hline LIQ & 0.00 & -2.33 & 4.56 & 0.13 & 0.28 & 0.20 & 0.14 \\
\hline Adj. $R^{2}$ & 0.25 & -0.20 & 0.87 & 0.19 & & & \\
\hline \multicolumn{8}{|c|}{ IRC Liquidity } \\
\hline MKT & 1.08 & -19.49 & 40.98 & 1.82 & 0.60 & 0.53 & 0.45 \\
\hline TERM & -0.03 & -7.94 & 5.74 & 0.42 & 0.27 & 0.20 & 0.14 \\
\hline DEF & 0.03 & -17.00 & 16.82 & 1.04 & 0.38 & 0.30 & 0.23 \\
\hline LIQ & -2.66 & -1294.19 & 1575.14 & 69.61 & 0.31 & 0.23 & 0.17 \\
\hline Adj. $\mathrm{R}^{2}$ & 0.25 & -0.19 & 0.85 & 0.19 & & & \\
\hline
\end{tabular}


Table 5. The Table reports cross-sectional regressions of excess returns on factor loadings in three sub-periods. The excess returns are averaged over all months in the period and $\beta_{\mathrm{MKT}}$, $\beta_{\text {TERM }}, \beta_{\text {DEF }}, \beta_{\text {LIQ }}$ are computed over the same months. Period 1 is from January 2004 to August 2008, period 2 is from September 2008 to August 2010, period 3 is from September 2010 to December 2014. The Table reports the coefficients of the regression (multiplied by 100), the t-statistics in italics and the adjusted $\mathrm{R}^{2}$ of the cross-sectional regression.

\begin{tabular}{|ccccccc|}
\hline & Intercept & $\beta_{\text {MKT }}$ & $\beta_{\text {TERM }}$ & $\beta_{\text {DEF }}$ & $\beta_{\text {LIQ }}$ & Adj. R $^{2}$ \\
& \multicolumn{7}{c}{ Amihud Liquidity factor } \\
Period 1 & -0.197 & -0.225 & 0.098 & -0.277 & 1.891 & 19.57 \\
& -21.92 & -39.52 & 3.84 & -33.97 & 37.37 & \\
Period 2 & 0.385 & 0.000 & 0.475 & 0.024 & 1.117 & 7.64 \\
& 18.14 & 0.01 & 20.15 & 1.55 & 8.92 & \\
Period 3 & -0.054 & 0.112 & -0.012 & 0.106 & -0.047 & 8.28 \\
& -5.47 & 29.80 & -0.39 & 14.26 & -1.17 & \\
& & & & & & \\
\hline Period 1 & -0.195 & -0.220 & 0.197 & -0.267 & 0.003 & 20.73 \\
& -22.86 & -45.11 & 8.63 & -35.16 & 17.30 & \\
Period 2 & 0.422 & -0.015 & 0.549 & 0.026 & 0.002 & 10.04 \\
& 19.87 & -1.67 & 23.49 & 1.74 & 10.20 & \\
Period 3 & -0.048 & 0.099 & -0.122 & 0.009 & -0.001 & 8.47 \\
& -4.75 & 21.56 & -3.91 & 1.10 & -18.00 & \\
\hline
\end{tabular}

The strong exposure to the bond market index raises the question of whether another corporate bond price index that is broadly available to investors accounts as a risk factor in individual corporate bond returns. While the set of corporate bond indices is very large, we conduct some robustness checks using other indices constructed over a smaller set of corporate bonds. In this paper we consider the BofA Merrill Lynch US Corporate Investment-grade or high yield index, as well as the Barclays US Investment-grade index. As these indices that we use for robustness are all classified into the two main investment categories, the comparison to our repeat-sales price index is thus not perfect. By design our repeat-sales index is constructed based on all bonds in the sample disregarding their characteristics. We were however not able to obtain any index which includes both categories. Finally we also assess the time series model using a stock market index (S\&P 500). As illustrated in Table 6, these alternative corporate bond indices also have an important explanatory power in the model, while the 
stock market factor has much less, as indicated by a lower percentage of significant t-statistics. While the various corporate bond indices thus appear as alternative measures of the market risk factor, our repeat-sales price index nevertheless presents the advantage of being constructed ad-hoc on the bonds available in the sample.

As reported in Tables 4 and 6 the loading on the bond market factor ranges between large negative and large positive values. It is interesting to investigate which kind of bonds exhibit such a negative exposure to the aggregate market factor. We therefore investigate the relation between the exposure and several bond characteristics. In fact very few bonds have negative market betas, as this applies to 1,583 issues in the overall sample, hence less than $10 \%$. As illustrated in Figure 6, bonds with a negative market beta are usually those bonds which have on average negative excess returns over the sample period. Hence those bonds which move in an opposite direction to the market are those bonds which on average have negative excess returns. It further appears that lower-rated bonds (higher rating on the numerical scale) and very short term bonds are most likely to exhibit negative exposures. Two phenomena can have an impact here. Low-rated bonds or junk bonds are subject to financial distress and are less likely to move in the market direction. Also bonds which are approaching their maturity are moving to their par value, regardless of how the aggregate market performs.

\subsection{Tests on bond portfolios}

The analysis of individual bond return series might be noisy and create large dispersion in the coefficient estimates. We therefore follow the portfolio approach often adopted in the literature. Bonds are grouped into seven rating portfolios based on their rating in the month. The rating is obtained as the average of the ratings provided by Moody's, Fitch and Standard and Poor's, when available. We first transform the rating to a numerical scale and then assign each bond to a group according to the Standard and Poor's notation (AAA, AA, A, BBB, BB, B and CCC and below). We account for possible rating changes over time and construct the portfolio excess return series over all months in the sample. The portfolio return series are then regressed on the risk factors to assess how much of the time series variation in portfolio returns is captured by the factors and in particular the market risk factor constructed with a repeat-sales index. 
Figure 6. The Figure displays the relation between bond characteristics and the market beta. The graphs respectively represents a bond's average excess return, its average rating and its average maturity along with its exposure to the market factor. The rating of each bond is obtained as the average of the ratings provided by Moody's, Fitch and Standard and Poor's, when available, and is transformed to a numerical scale ranging from 1 (for AAA rated bonds) to 21 (for $\mathrm{D}$ rated bonds). The sample contains 16,213 individual bonds. All variables are constructed monthly and the period is from January 2004 to December 2014.
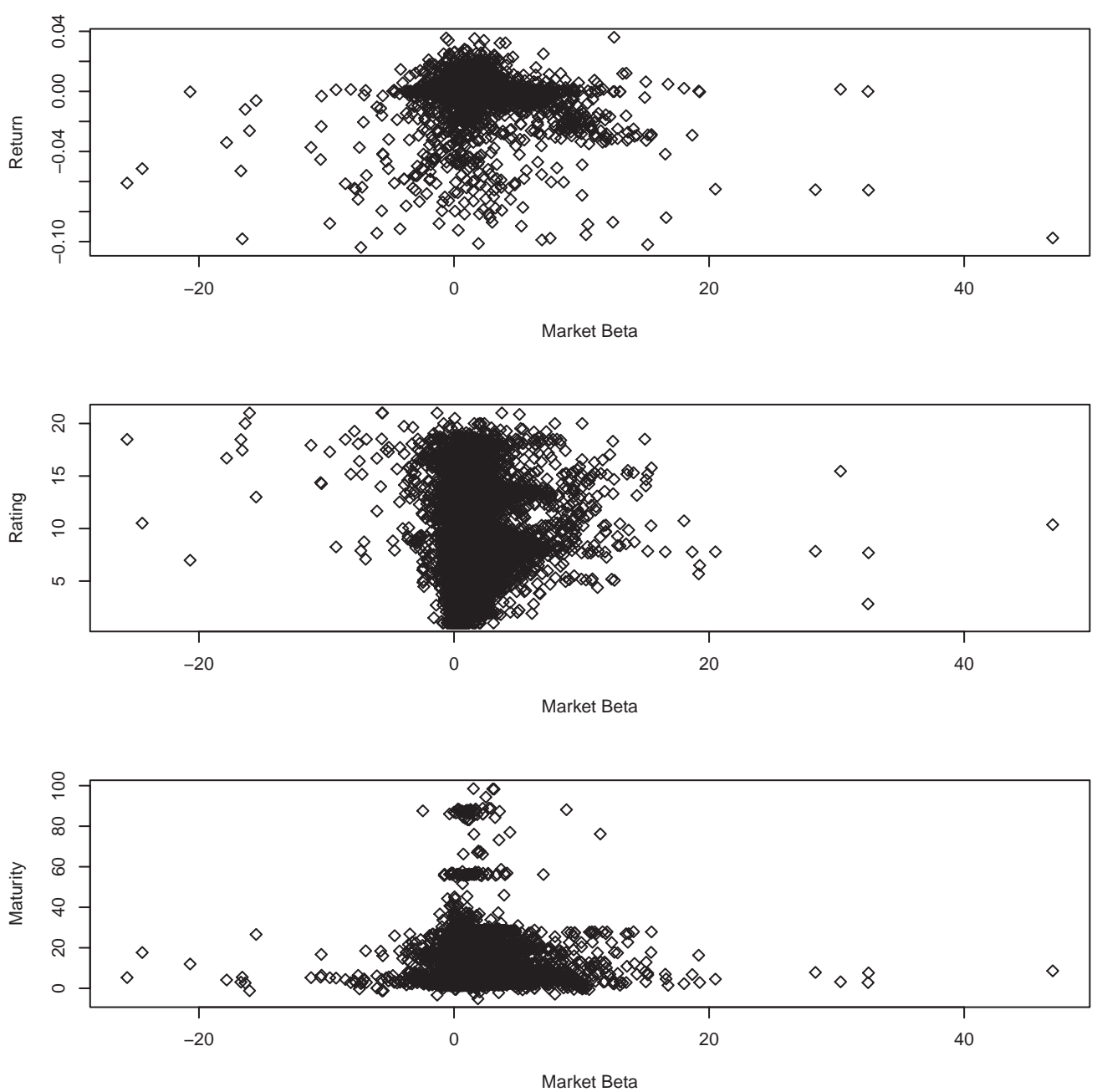
Table 6. The Table reports full-period estimates of betas associated with bond market return, term, default and liquidity factors. MKT is the bond market index excess return obtained from different sources: the BofA Merrill Lynch investment-grade and high yield indices, and the Barclays US Corporate Bond index. TERM is the term premium constructed as the yield difference between long-term Treasury bonds and short-term Treasury notes. DEF is the default premium and is constructed as the return difference between BofA Merrill Lynch's BB and AAA corporate bond indices. The liquidity factor is obtained using the Amihud illiquidity measure. The Table reports distribution statistics of the betas obtained on the different factors and the percentage of bonds that exhibit significant coefficients at the $10 \%, 5 \%$ and $1 \%$ statistical significance levels. The sample contains 16,213 individual bonds. All variables are constructed monthly and the period is from January 2004 to December 2014.

\begin{tabular}{|c|c|c|c|c|c|c|c|}
\hline \multirow[b]{2}{*}{ Variable } & \multicolumn{7}{|c|}{ BofA IG } \\
\hline & Mean & Minimum & Maximum & s.d. & \%bonds & $\%_{\text {bonds }}$ & \%bonds \\
\hline MKT & 0.84 & -19.62 & 36.53 & 1.49 & 0.59 & 0.51 & 0.44 \\
\hline TERM & -0.04 & -9.51 & 6.01 & 0.46 & 0.23 & 0.16 & 0.11 \\
\hline DEF & 0.30 & -19.70 & 18.43 & 1.02 & 0.42 & 0.35 & 0.28 \\
\hline LIQ & 0.00 & -3.27 & 4.38 & 0.12 & 0.26 & 0.19 & 0.12 \\
\hline \multirow[t]{2}{*}{ Adj. $\mathrm{R}^{2}$} & 0.23 & -0.21 & 0.89 & 0.19 & & & \\
\hline & \multicolumn{7}{|c|}{ BofA HY } \\
\hline MKT & 0.84 & -17.53 & 36.36 & 1.51 & 0.56 & 0.48 & 0.40 \\
\hline TERM & -0.03 & -10.07 & 5.56 & 0.41 & 0.24 & 0.17 & 0.11 \\
\hline DEF & -0.38 & -39.22 & 22.09 & 1.58 & 0.35 & 0.27 & 0.20 \\
\hline LIQ & -0.01 & -3.19 & 2.80 & 0.12 & 0.29 & 0.21 & 0.15 \\
\hline \multirow[t]{2}{*}{ Adj. $R^{2}$} & 0.22 & -0.21 & 0.18 & & & & \\
\hline & \multicolumn{7}{|c|}{ Barclays IG } \\
\hline MKT & 0.79 & -22.86 & 16.73 & 1.44 & 0.53 & 0.46 & 0.39 \\
\hline TERM & 0.04 & -9.67 & 7.35 & 0.39 & 0.31 & 0.24 & 0.17 \\
\hline $\mathrm{DEF}$ & 0.33 & -17.46 & 20.25 & 0.99 & 0.39 & 0.31 & 0.24 \\
\hline LIQ & 0.00 & -1.98 & 1.89 & 0.12 & 0.25 & 0.18 & 0.12 \\
\hline \multirow[t]{2}{*}{ Adj. $R^{2}$} & 0.21 & -0.19 & 0.84 & 0.18 & & & \\
\hline & \multicolumn{7}{|c|}{ Stock market index } \\
\hline MKT & 0.08 & -7.71 & 10.18 & 0.53 & 0.26 & 0.19 & 0.13 \\
\hline TERM & 0.11 & -6.94 & 5.67 & 0.36 & 0.42 & 0.34 & 0.26 \\
\hline $\mathrm{DEF}$ & 0.41 & -22.46 & 17.58 & 1.17 & 0.42 & 0.34 & 0.28 \\
\hline LIQ & -0.02 & -2.72 & 1.84 & 0.12 & 0.29 & 0.21 & 0.15 \\
\hline Adj. $\mathrm{R}^{2}$ & 0.16 & -0.21 & 0.86 & 0.16 & & & \\
\hline
\end{tabular}


For the bond market risk factor we consider an additional specification. Since the repeat-sales estimator can readily be applied to any sub-sample of bonds, we design a repeat-sales price index that is specific to each portfolio. For the index construction in a rating group we consider all bonds in the database with this rating, which satisfy the additional condition of having at least 35 monthly observations available over the whole sample period. We assess whether such a rating-specific index is superior to the total market index in our asset pricing tests.

Table 7 reports full-sample time series estimates of the factor loadings of the portfolios. We consider four different specifications of the time-series regression. The first is without including the repeat-sales price index. The second is without including the liquidity factor, since it might be correlated with the price index factor. The third is by considering the aggregate market repeat-sales price index and the fourth is by considering the rating-specific repeat-sales price index. The index factor plays an important role as indicated by the increase in the adjusted $R^{2}$ values once this factor is included. It is highly significant in the regressions and the associated loading increases as the rating of the portfolio decreases. Considering the rating-specific index further increases the $\mathrm{R}^{2}$ by a few percentage points except for speculative grade BB bonds. It suggests that the index specifically designed for the portfolio captures an important fraction of the time series variation in the portfolio return beyond the variation captured by the aggregate market index. At the same time introducing the market risk factor reduces coefficients on other factors suggesting that the market factor captures an important fraction of the time series variation in bond portfolio returns, as was the case as well for individual bond returns.

We can be more precise in the portfolio approach by considering 16 rating-specific portfolios with three maturity groups in each. Each rating from AAA to B- (according to S\&P's notation) is used to create individual portfolios and all bonds with ratings below $\mathrm{B}$ - are assigned to the last portfolio. Inside each rating group, the bond is assigned to one of the three maturity groups, based on whether its remaining time to maturity is below 5 years, between 5 and 15 years or above 15 years. Results of the time series regressions of portfolio excess returns on the risk factors are provided in Table 8. t-statistics of the market beta indicate a significant exposure to the bond market risk factor, which increases as the rating of the portfolio decreases. Further, it appears that short-term bonds have a weaker exposure as the average market beta of short term bonds is below its value for middle and long term bonds. 
Table 7. The Table reports results of time-series regressions of portfolio excess returns on several risk factors. Portfolios are formed each month in 7 rating groups (from AAA to CCC and below). The dependent variable is a portfolio's monthly excess return over the risk-free rate. MKT is the bond market index excess return obtained from a repeat-sales estimation over all bonds in the sample, with at least 35 monthly observations. TERM is the term premium constructed as the yield difference between long-term Treasury bonds and short-term Treasury notes. DEF is the default premium and is constructed as the return difference between BofA Merrill Lynch's $\mathrm{BB}$ and $\mathrm{AAA}$ corporate bond indices. Liquidity factors are obtained using the Amihud illiquidity measure. MKT is excluded from model (1) and liquidity is removed from model (2). MKT represents the whole market in model (3) and is rating-specic in model (4). t-statistics are in italics.

\begin{tabular}{|c|c|c|c|c|c|c|c|c|c|c|c|c|}
\hline & \multicolumn{4}{|c|}{ AAA } & \multicolumn{4}{|c|}{ AA } & \multicolumn{4}{|c|}{ A } \\
\hline & (1) & (2) & (3) & (4) & (1) & (2) & (3) & (4) & (1) & (2) & (3) & $(4)$ \\
\hline \multirow[t]{2}{*}{ Const. } & -0.002 & -0.001 & -0.001 & -0.001 & -0.001 & 0.000 & 0.000 & 0.000 & -0.002 & 0.000 & 0.000 & -0.001 \\
\hline & -1.94 & -1.15 & -1.38 & -3.42 & -0.95 & 1.17 & 1.01 & -1.40 & -1.40 & -0.30 & -0.20 & -2.37 \\
\hline \multirow[t]{2}{*}{ Market } & & 0.773 & 0.761 & 1.009 & & 0.684 & 0.684 & 1.109 & & 1.128 & 1.126 & 1.201 \\
\hline & & 16.26 & 15.28 & 50.71 & & 31.89 & 29.49 & 48.78 & & 46.21 & 43.88 & 44.60 \\
\hline \multirow[t]{2}{*}{ Term } & 0.138 & 0.018 & 0.017 & -0.011 & 0.104 & -0.004 & -0.004 & -0.015 & 0.174 & -0.004 & -0.004 & -0.036 \\
\hline & 5.82 & 1.18 & 1.07 & -1.88 & 5.62 & -0.58 & -0.61 & -3.22 & 5.91 & -0.55 & -0.52 & -4.34 \\
\hline \multirow[t]{2}{*}{ Default } & 0.091 & -0.256 & -0.276 & 0.043 & 0.261 & -0.068 & -0.069 & 0.037 & 0.299 & -0.231 & -0.244 & -0.022 \\
\hline & 1.77 & -7.08 & -7.25 & 4.05 & 6.50 & -4.18 & -3.88 & 3.81 & 4.67 & -12.44 & -12.45 & -1.34 \\
\hline \multirow[t]{2}{*}{ Liquidity } & -0.020 & & -0.006 & -0.001 & -0.012 & & 0.000 & 0.002 & -0.024 & & -0.003 & -0.001 \\
\hline & -2.79 & & -1.48 & -0.92 & -2.19 & & 0.03 & 1.27 & -2.66 & & -1.58 & -0.29 \\
\hline \multirow[t]{3}{*}{ Adj. $\mathrm{R}^{2}$} & 0.25 & 0.74 & 0.75 & 0.97 & 0.39 & 0.93 & 0.93 & 0.97 & 0.33 & 0.96 & 0.96 & 0.96 \\
\hline & & & BB & & & B & B & & & & B & \\
\hline & $(1)$ & (2) & (3) & $(4)$ & $(1)$ & (2) & (3) & $(4)$ & $(1)$ & $(2)$ & (3) & $(4)$ \\
\hline \multirow[t]{2}{*}{ Const. } & -0.003 & -0.001 & -0.001 & -0.002 & -0.004 & -0.001 & -0.001 & -0.002 & -0.008 & -0.005 & -0.005 & -0.005 \\
\hline & -2.06 & -1.91 & -1.96 & -3.47 & -1.64 & -0.95 & -0.90 & -1.31 & -3.34 & -3.33 & -3.31 & -3.51 \\
\hline \multirow[t]{2}{*}{ Market } & & 1.071 & 1.063 & 1.148 & & 1.388 & 1.377 & 1.147 & & 1.246 & 1.302 & 0.835 \\
\hline & & 26.94 & 24.61 & 27.73 & & 13.59 & 12.39 & 10.34 & & 10.86 & 10.84 & 12.31 \\
\hline \multirow[t]{2}{*}{ Term } & 0.154 & -0.016 & -0.015 & -0.027 & 0.101 & -0.120 & -0.118 & -0.011 & 0.132 & -0.068 & -0.075 & 0.006 \\
\hline & 5.20 & -1.26 & -1.11 & -2.15 & 2.18 & -3.64 & -3.35 & -0.30 & 2.84 & -1.84 & -1.97 & 0.18 \\
\hline \multirow[t]{2}{*}{ Default } & 0.487 & -0.025 & -0.026 & 0.006 & 0.809 & 0.149 & 0.145 & -0.072 & 1.268 & 0.575 & 0.640 & 0.385 \\
\hline & 7.60 & -0.83 & -0.78 & 0.20 & 8.05 & 1.92 & 1.71 & -0.64 & 12.56 & 6.59 & 6.98 & 3.93 \\
\hline \multirow[t]{2}{*}{ Liquidity } & -0.021 & & -0.002 & -0.001 & -0.030 & & -0.005 & -0.006 & 0.004 & & 0.028 & 0.018 \\
\hline & -2.35 & & -0.50 & -0.24 & -2.10 & & -0.48 & -0.60 & 0.31 & & 2.75 & 1.90 \\
\hline Adj. $R^{2}$ & 0.44 & 0.91 & 0.91 & 0.93 & 0.46 & 0.77 & 0.77 & 0.72 & 0.62 & 0.80 & 0.81 & 0.83 \\
\hline
\end{tabular}




\begin{tabular}{|ccccc|}
\hline & \multicolumn{4}{c|}{ CCC } \\
& $(1)$ & $(2)$ & $(3)$ & $(4)$ \\
\hline Const. & -0.012 & -0.010 & -0.009 & -0.009 \\
& -2.70 & -2.47 & -2.30 & -2.65 \\
Market & & 1.388 & 1.516 & 0.748 \\
& & 4.68 & 4.96 & 9.15 \\
Term & 0.210 & -0.016 & -0.030 & 0.183 \\
& 2.30 & -0.17 & -0.31 & 2.61 \\
Default & 2.255 & 1.356 & 1.524 & 1.180 \\
& 11.34 & 6.02 & 6.53 & 6.15 \\
Liquidity & 0.047 & & 0.074 & 0.041 \\
& 1.65 & & 2.83 & 1.93 \\
Adj. R ${ }^{2}$ & 0.55 & 0.59 & 0.62 & 0.74 \\
\hline
\end{tabular}

Table 8. The Table reports results of time-series regressions of portfolio excess returns on several risk factors. Portfolios are formed each month in 16 rating groups (from AAA to B-and below) and further classified into three maturity groups (below 5 years, between 5 and 15 years and above 15 years). The dependent variable is a portfolio's monthly excess return over the risk-free rate. It is described in percentage in the column Return. MKT is the bond market index excess return obtained from a repeat-sales estimation over all bonds in the sample, with at least 35 monthly observations. TERM is the term premium constructed as the yield difference between long-term Treasury bonds and short-term Treasury notes. DEF is the default premium and is constructed as the return difference between BofA Merrill Lynch's BB and AAA corporate bond indices. Liquidity factors are obtained using the Amihud illiquidity measure. t-statistics are in italics next to the coefficient.

\begin{tabular}{|ccccccccccccc|}
\hline Rating & Return Const. & \multicolumn{1}{c}{ Market } & \multicolumn{1}{c}{ Term } & Default & Liquidity & Adj. $\mathbf{R}^{2}$ \\
\hline \multicolumn{1}{c}{} & \multicolumn{1}{c}{ Maturity $\leq 5$ years } \\
\hline AAA & -0.11 & -0.08 & -2.43 & 0.27 & 10.58 & -0.01 & -1.66 & -0.08 & -3.88 & 0.00 & -1.07 & 0.57 \\
AA+ & 0.14 & 0.15 & 1.73 & 0.43 & 6.89 & -0.03 & -1.64 & 0.05 & 1.08 & 0.00 & 0.12 & 0.49 \\
AA & 0.03 & 0.02 & 0.31 & 0.37 & 7.84 & 0.00 & -0.13 & 0.07 & 1.95 & 0.00 & 0.27 & 0.59 \\
AA- & 0.03 & 0.05 & 0.73 & 0.50 & 10.86 & -0.01 & -0.83 & 0.04 & 1.08 & 0.00 & -0.83 & 0.71 \\
A+ & 0.00 & 0.09 & 1.96 & 0.61 & 18.11 & -0.04 & -3.83 & -0.18 & -6.86 & 0.00 & 0.22 & 0.78 \\
A & -0.09 & -0.01 & -0.33 & 0.61 & 19.71 & -0.06 & -5.91 & -0.19 & -7.92 & -0.01 & -2.04 & 0.81 \\
A- & -0.17 & -0.10 & -1.13 & 1.00 & 15.98 & -0.07 & -3.76 & -0.19 & -3.92 & -0.01 & -1.18 & 0.77 \\
BBB+ & -0.06 & -0.06 & -1.07 & 0.58 & 13.45 & 0.00 & 0.13 & 0.10 & 2.99 & 0.00 & 1.00 & 0.80 \\
BBB & -0.23 & -0.22 & -2.59 & 0.61 & 9.74 & -0.07 & -3.31 & -0.01 & -0.19 & -0.01 & -1.70 & 0.64 \\
BBB- & -0.08 & -0.09 & -1.20 & 0.73 & 13.65 & -0.02 & -0.95 & 0.11 & 2.69 & 0.00 & -0.76 & 0.81 \\
BB+ & -0.03 & 0.07 & 0.39 & 1.38 & 9.76 & -0.10 & -2.26 & -0.09 & -0.85 & 0.03 & 2.09 & 0.56
\end{tabular}




\begin{tabular}{|c|c|c|c|c|c|c|c|c|c|c|c|c|}
\hline BB & -0.11 & -0.05 & -0.24 & 1.49 & 10.57 & -0.19 & -4.25 & -0.10 & -0.91 & 0.00 & 0.29 & 0.63 \\
\hline BB- & -0.26 & -0.33 & -2.23 & 0.91 & 8.30 & -0.01 & -0.38 & 0.29 & 3.48 & -0.01 & -1.32 & 0.69 \\
\hline $\mathrm{B}+$ & -0.05 & -0.15 & -1.25 & 0.57 & 6.49 & -0.04 & -1.60 & 0.41 & 6.06 & 0.00 & 0.12 & 0.70 \\
\hline B & -0.45 & -0.52 & -3.16 & 1.19 & 9.68 & -0.07 & -1.88 & 0.36 & 3.87 & 0.03 & 2.51 & 0.71 \\
\hline $\begin{array}{l}\mathrm{B}-\text { and } \\
\text { below }\end{array}$ & -0.37 & -0.63 & -2.00 & 1.22 & 5.23 & -0.03 & -0.44 & 1.30 & 7.30 & 0.07 & 3.54 & 0.66 \\
\hline \multicolumn{13}{|c|}{ Maturity $>5$ and $\leq 15$ years } \\
\hline AAA & -0.07 & 0.00 & 0.05 & 0.84 & 11.95 & 0.02 & 0.88 & -0.34 & -6.25 & -0.02 & -3.11 & 0.67 \\
\hline $\mathrm{AA}+$ & 0.16 & 0.12 & 1.17 & 0.52 & 6.93 & 0.00 & -0.10 & 1.12 & 2.01 & 0.00 & 0.37 & 0.54 \\
\hline $\mathrm{AA}$ & -0.15 & -0.17 & -1.61 & 0.64 & 8.18 & 0.00 & -0.18 & 0.00 & 0.07 & 0.00 & -0.08 & 0.54 \\
\hline AA- & -0.06 & -0.11 & -1.14 & 0.92 & 12.95 & -0.03 & -1.19 & 0.11 & 1.99 & 0.00 & 0.38 & 0.78 \\
\hline $\mathrm{A}_{+}$ & -0.03 & 0.04 & 0.52 & 1.14 & 22.71 & -0.06 & -4.05 & -0.23 & -6.02 & 0.00 & -0.86 & 0.87 \\
\hline A & -0.13 & -0.10 & -1.27 & 1.14 & 20.30 & -0.01 & -0.39 & -0.18 & -4.17 & -0.01 & -2.56 & 0.86 \\
\hline A- & -0.08 & 0.11 & 0.94 & 2.07 & 23.07 & -0.11 & -3.89 & -0.53 & -7.75 & -0.01 & -1.77 & 0.86 \\
\hline $\mathrm{BBB}+$ & 0.04 & 0.05 & 0.75 & 1.13 & 22.23 & 0.01 & 0.86 & -0.01 & -0.31 & 0.01 & 1.32 & 0.89 \\
\hline BBB & -0.24 & -0.23 & -2.09 & 1.29 & 16.03 & -0.05 & -1.88 & -0.13 & -2.10 & -0.01 & -1.56 & 0.80 \\
\hline BBB- & -0.02 & -0.06 & -0.56 & 1.05 & 13.54 & -0.03 & -1.36 & 0.15 & 2.48 & 0.01 & 1.39 & 0.79 \\
\hline $\mathrm{BB}+$ & -0.18 & -0.20 & -0.71 & 1.54 & 7.15 & -0.20 & -2.90 & 0.05 & 0.30 & -0.01 & -0.49 & 0.50 \\
\hline $\mathrm{BB}$ & 0.04 & -0.03 & -0.21 & 1.10 & 9.01 & -0.09 & -2.23 & 0.30 & 3.25 & 0.00 & -0.14 & 0.70 \\
\hline BB- & -0.26 & -0.43 & -2.31 & 1.24 & 8.91 & -0.07 & -1.68 & 0.56 & 5.23 & 0.00 & -0.23 & 0.75 \\
\hline $\mathrm{B}+$ & -0.27 & -43 & -2.65 & 0.68 & 5.66 & -0.07 & -1.76 & 0.54 & 5.81 & -0.01 & -0.69 & 0.68 \\
\hline $\mathrm{B}$ & -0.32 & -0.35 & -1.52 & 1.71 & 10.03 & -0.14 & -2.54 & 0.20 & 1.53 & 0.00 & 0.29 & 0.68 \\
\hline $\begin{array}{l}\mathrm{B}-\text { and } \\
\text { below }\end{array}$ & -0.17 & -0.48 & -1.62 & 1.44 & 6.55 & 0.04 & 0.63 & 1.43 & 8.54 & 0.06 & 3.17 & 0.74 \\
\hline
\end{tabular}


Table 8 con't.

\begin{tabular}{|c|c|c|c|c|c|c|c|c|c|c|c|c|}
\hline Rating & Return & Const. & & Market & & Term & & Default & & Liquidity & & Adj. $R^{2}$ \\
\hline \multicolumn{13}{|c|}{ Maturity $>15$ years } \\
\hline AAA & -0.09 & 0.04 & 0.24 & 1.26 & 11.31 & 0.00 & -0.08 & -0.60 & -7.09 & -0.01 & -0.67 & 0.60 \\
\hline $\mathrm{AA}+$ & 0.17 & 0.07 & 0.48 & 0.86 & 7.42 & 0.00 & -0.02 & -0.03 & -0.32 & 0.01 & 1.34 & 0.44 \\
\hline $\mathrm{AA}$ & -0.04 & -0.05 & -0.38 & 0.90 & 8.54 & 0.07 & 2.04 & -0.11 & -1.41 & 0.00 & 0.55 & 0.54 \\
\hline $\mathrm{AA}-$ & -0.06 & -0.08 & -0.99 & 0.99 & 17.25 & 0.01 & 0.32 & -0.06 & -1.34 & 0.01 & 2.17 & 0.82 \\
\hline $\mathrm{A}_{+}$ & 0.02 & 0.04 & 0.45 & 1.22 & 19.21 & -0.01 & -0.27 & -0.22 & -4.60 & 0.00 & -0.63 & 0.83 \\
\hline A & -0.12 & -0.11 & -0.98 & 1.33 & 15.54 & 0.10 & 3.80 & -0.14 & -2.09 & 0.00 & 0.38 & 0.80 \\
\hline A- & 0.08 & 0.09 & 0.80 & 1.45 & 16.70 & 0.05 & 1.70 & -0.06 & -0.97 & 0.00 & -0.11 & 0.83 \\
\hline $\mathrm{BBB}+$ & 0.04 & 0.04 & 0.43 & 1.40 & 19.05 & 0.03 & 1.45 & -0.10 & -1.85 & 0.00 & 0.43 & 0.85 \\
\hline BBB & -0.23 & -0.20 & -1.38 & 1.78 & 16.91 & -0.06 & -1.68 & -0.24 & -2.95 & -0.01 & -0.59 & 0.80 \\
\hline BBB- & 0.08 & 0.02 & 0.13 & 1.38 & 12.37 & -0.01 & -0.24 & 0.21 & 2.43 & 0.01 & 1.27 & 0.76 \\
\hline $\mathrm{BB}+$ & -0.11 & -0.03 & -0.11 & 2.21 & 9.68 & -0.30 & -4.18 & -0.31 & -1.78 & -0.03 & -1.31 & 0.58 \\
\hline $\mathrm{BB}$ & -0.12 & -0.16 & -0.52 & 2.40 & 10.43 & -0.25 & -3.56 & 0.01 & 0.09 & 0.00 & 0.07 & 0.67 \\
\hline BB- & -0.02 & -0.23 & -0.79 & 1.08 & 4.87 & -0.13 & -1.87 & 0.59 & 3.53 & 0.00 & 0.20 & 0.54 \\
\hline $\mathrm{B}+$ & 0.02 & -0.20 & -0.74 & 1.30 & 6.47 & -0.19 & -3.09 & 0.57 & 3.78 & 0.00 & -0.22 & 0.66 \\
\hline B & 0.06 & 0.03 & 0.08 & 2.11 & 9.29 & -0.31 & -4.43 & 0.00 & 0.02 & -0.05 & -2.43 & 0.67 \\
\hline $\begin{array}{l}\text { B- and } \\
\text { below }\end{array}$ & -0.63 & -0.98 & -1.47 & 1.39 & 2.79 & -0.23 & -1.47 & 0.81 & 2.13 & -0.02 & -0.39 & 0.29 \\
\hline
\end{tabular}

Figure 7 provides a first indication on the cross-sectional relation of the exposure of bond portfolio's excess returns to the market factor. The graph indicates that for bonds with a maturity below 5 years, there appears to be a negative relation between excess returns and betas suggesting a negative risk premium on the market factor. This is in line with the evidence reported for individual cross-sectional regressions where risk premiums turned negative in some periods. However, the cross-sectional regression of these 16 portfolio excess returns on market exposure is statistically not significant. The relation might emerge from the large negative returns that are observed for some portfolios over the sample period. The financial crisis period is characterised by large negative returns in all portfolios. Afterwards, many portfolios continue to exhibit negative excess returns, suggesting a large disinvestment from this market. Rating changes in response to the crisis might have created additional pressure in this market, as the financial crisis was followed by numerous downgrades, leading to price decreases and therefore to the absence of returns for investors. 
$114 \quad$ Finance $\mathrm{Vol} .37=\mathrm{N}^{\circ} 2=2016$

Figure 7. The Figure displays the relation between portfolio excess returns and market beta. Portfolios are formed each month in 16 rating groups (from AAA to B- and below) and further classified into three maturity groups (below 5 years, between 5 and 15 years and above 15 years). The sample contains 16,213 individual bonds. All variables are constructed monthly and the period is from January 2004 to December 2014.
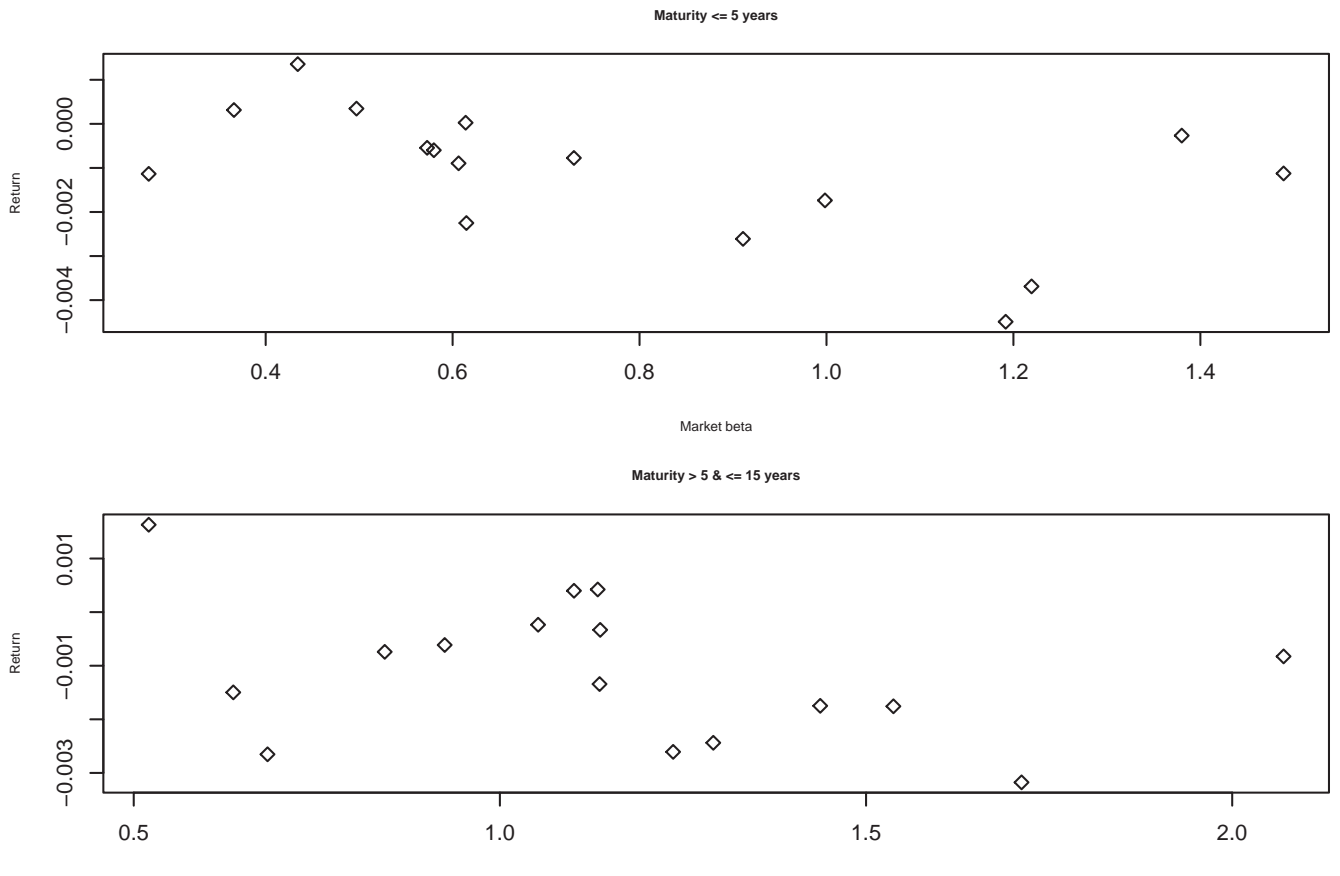

Market beta

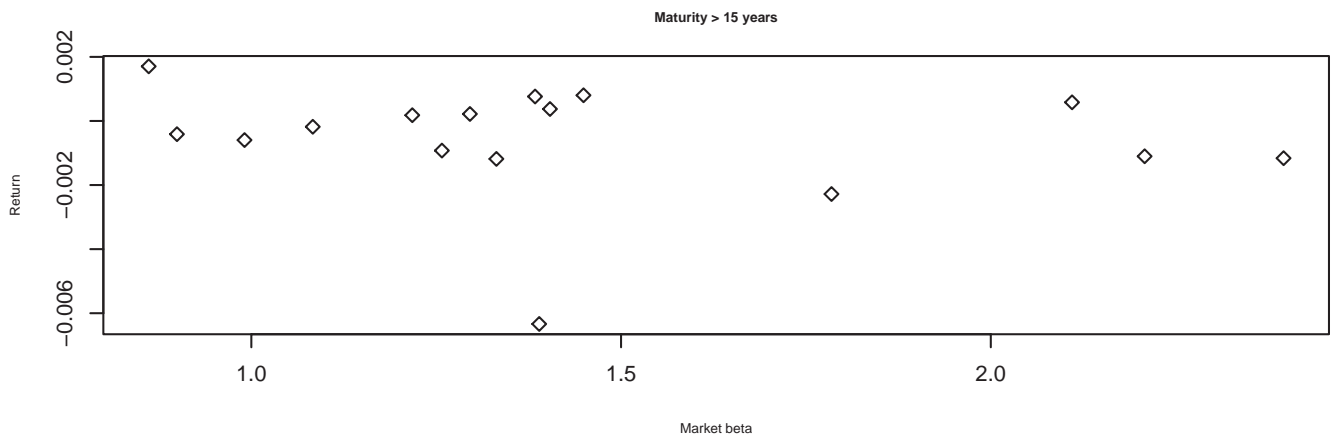




\section{Conclusion}

The recent financial crisis has highlighted the importance of reliable price benchmarks in particular for securities traded in opaque over-the-counter markets. The US corporate bond market is a market where several different price indices are provided (mostly by investment banks), but few are comparable among each other and none of them reflects the aggregate market price evolution. In this paper we use a repeat-sales price index methodology to construct a reliable price index of the US corporate bond market. The methodology is less sophisticated on the characteristics of the securities it relies on but therefore is very comprehensive and can include observations on all transactions in the market. Repeat-sales indices are particularly appealing when there is no continuous trading or when there are only a few observed trades at irregular time intervals. In such a setting the construction of an aggregate index is often reduced to an arithmetic price average over the available observations. We show in this paper that repeat-sales indices are superior to mean price indices in the specific setting of the US market for corporate bonds. We consider several specifications of the repeat-sales index: a value- or interval-weighted index estimated simultaneously, or a chainweighted index. The performance of the various estimates is assessed over the arithmetic average of available prices. Performance tests based on Mincer and Zarnowitz (1969) and Diebold and Mariano (1995) test statistics show that repeat-sales price index estimations are superior to arithmetic price averages.

Constructing such an aggregate corporate bond market index is particularly appealing as it can be used in asset pricing studies. Surprisingly there has been no study considering the cross-section of corporate bond returns and their exposure to a bond market index as it is typically the case in the stock market literature. Most studies of corporate bond returns consider risk factors derived from stock markets as well as term, default and liquidity factors in the bond market. We show that beyond these factors, including the bond market index as a systematic risk factor considerably increases the explanatory power of the regressions. Further we show that this exposure to the market index increases as the rating of the bond decreases. Finally the repeat-sales procedure is also useful in designing a rating-specific index which, in some instances, displays a better ability to explain the cross-section of corporate bond portfolios formed on the bond's rating. 


\section{References}

Acharya, V. V., Amihud, Y., and Bharath, S. T. (2013). Liquidity risk of corporate bond returns: A conditional approach. Jounal of Financial Economics, 110(2): 358-386.

Amihud, Y. (2002). Illiquidity and stock returns: Cross-section and time-series effects. Journal of Financial Markets, 5(1): 31-56.

Ashenfelter, O. and Graddy, K. (2003). Auctions and the price of art. Journal of Economic Literature, 41(3): 763-787.

Bailey, M. J., Muth, R. F., and Nourse, H. O. (1963). A regression method for real estate price index construction. Journal of the American Statistical Association, 58(304): 933-942.

Beaupain, R. and Durré, A. (2011). Inferring trading dynamics for an OTC market: The case of the euro area overnight money market. Quantitative Finance, 11(9): 1285-1295.

Bollerslev, T., Patton, A. J., and Wang, W. (2015). Daily house price indexes: Construction, modeling, and longer-run predictions. Journal of Applied Econometrics, 31(6): 1005-1025.

Bongaerts, D., De Jong, F., and Driessen, J. (2011). Derivative pricing with liquidity risk: Theory and evidence from the credit default swap market. Journal of Finance, 66(1): 203-240.

Brown, P. (2002). Constructing and calculating bond indices. Cambridge: Gilmour Drummond Publishing.

Case, K. E. and Shiller, R. J. (1987). Prices of single family homes since 1970: New indexes for four cities. Working Paper, NBER.

Case, K. E. and Shiller, R. J. (1989). The efficiency of the market for single-family homes. American Economic Review, 79(1): 125-137.

Crone, T. M. and Voith, R. P. (1992). Estimating house price appreciation: A comparison of methods. Journal of Housing Economics, 2(4): 324-338.

Dick-Nielsen, J. (2009). Liquidity biases in TRACE. Journal of Fixed Income, 19(2): 43-55.

Dick-Nielsen, J., Feldhütter, P., and Lando, D. (2012). Corporate bond liquidity before and after the onset of the subprime crisis. Journal of Financial Economics, 103(3): 471-492.

Diebold, F. X. and Mariano, R. S. (1995). Comparing predictive accuracy. Journal of Business and Economic Statistics, 13(3): 253-263.

Dimson, E., Rousseau, P. L., and Spaenjers, C. (2015). The price of wine. Journal of Financial Economics, 118(2): 431-449.

Edwards, A. K., Harris, L. E., and Piwowar, M. S. (2007). Corporate bond market transaction costs and transparency. Journal of Finance, 62(3): 1421-1451. 
Elton, E. J., Gruber, M. J., Das, S., and Hlavka, M. (1993). Efficiency with costly information: A reinterpretation of evidence from managed portfolios. Review of Financial Studies, 6(1): 1-22.

Fama, E. F. and French, K. R. (1993). Common risk factors in the returns on stocks and bonds. Journal of Financial Economics, 33(1): 3-56.

Feldhütter, P. (2012). The same bond at different prices: Identifying search frictions and selling pressures. Review of Financial Studies, 25(4): 1155-1206.

Gebhardt, W. R., Hvidkjaer, S., and Swaminathan, B. (2005). The cross-section of expected corporate bond returns: Betas or characteristics? Journal of Financial Economics, 75(1): 85-114.

Goetzmann, W. N. (1992). The accuracy of real estate indices: Repeat sale estimators. Journal of Real Estate Finance and Economics, 5(1): 5-53.

Goltz, F. and Campani, C. H. (2011). A review of corporate bond indices: Construction principles, return heterogeneity, and fluctuations in risk exposures. Working Paper, EDHEC Risk Institute.

Harris, L. E. and Piwowar, M. S. (2006). Secondary trading costs in the municipal bond market. Journal of Finance, 61(3): 1361-1397.

Hill, C. R., Knight, J. R., and Sirmans, C. F. (1997). Estimating capital asset price indexes. Review of Economics and Statistics, 79(2): 226-233.

Lin, H., Wang, J., and Wu, C. (2011). Liquidity risk and expected corporate bond returns. Journal of Financial Economics, 99(3): 628-650.

Maalaoui Chun, O., Dionne, G., and François, P. (2014). Credit spread changes within switching regimes. Journal of Banking and Finance, 49(1): 41-55.

Martellini, L., Priaulet, P., and Priaulet, S. (2003). Fixed-income securities. Chichester: John Wiley \& Sons.

Mincer, J. A. and Zarnowitz, V. (1969). The evaluation of economic forecasts. In Mincer, J., editor, Economic Forecasts and Expectations: Analysis of Forecasting Behavior and Performance, pages 3-46. NBER.

Shiller, R. J. (1991). Arithmetic repeat sales price estimators. Journal of Housing Economics, 1(1): 110-126.

Shiller, R. J. (1993). Macro Markets. Clarendon Press.

Spiegel, M. and Starks, L. (2016). Institutional rigidities and bond returns around rating changes. WP, University of Texas and Yale School of Management.

Standard\&Poor's (2014). SerP/Case-Shiller Home Price Indices Methodology. S\&P Dow Jones Indices, McGraw Hill Financial.

Wang, F. T. and Zorn, P. M. (1997). Estimating house price growth with repeat sales data: What's the aim of the game? Journal of Housing Economics, 6(2): 93-118.

Wilko, S. (2013). A municipal bond market index based on a repeat sales methodology. Working Paper, US Securities and Exchange Commission. 